\title{
Relationship between welding conditions, abnormal grain growth and mechanical performance in friction-stir welded 6061-T6 aluminum alloy
}

\author{
Alexander Kalinenko, Igor Vysotskii , Sergey Malopheyev, Sergey Mironov *, Rustam Kaibyshev \\ Laboratory of Mechanical Properties of Nanoscale Materials and Superalloys, Belgorod National Research University, Pobeda 85, Belgorod, 308015, Russia
}

\section{A R T I C L E I N F O}

\section{Keywords:}

Characterization

Aluminium alloys

Plasticity methods

Grains and interfaces

Plasticity

\begin{abstract}
A B S T R A C T
In this work, a relationship between welding conditions, annealing behavior, and mechanical performance of friction-stir welded (FSWed) 6061-T6 aluminum alloy was examined. In the entire studied FSW range, the welded material was found to be unstable against abnormal grain growth during post-weld solutionizing treatment. However, a lowering of the FSW heat input tended to inhibit this undesirable phenomenon. In addition to the stir zone, the abnormal microstructural coarsening was also observed in the heat-affected zone, whereas the thermo-mechanically affected zone experienced static recrystallization. In all cases, the abnormal grain growth was found to result in $\sim 25-35^{\circ}<110>$ rotation of the original crystallographic texture. Hence, this process was suggested to be governed by the orientation-growth mechanism. Due to the relatively high strainhardening ability intrinsic to the coarse-grained materials, the abnormal grains suppressed tensile strain in the stir zone during transverse tensile tests thus degrading weld ductility.
\end{abstract}

\section{Introduction}

Friction-stir welding (FSW) is an innovative solid-state joining technique $[1,2]$, which is sometimes considered as one of the most significant recent achievements in the field of welding and joining. Unfortunately, a substantial drawback of this technology is relatively low stability of the welded materials against the abnormal grain growth [1]. This undesirable phenomenon occurs during post-weld heat treatment and involves catastrophic growth of a few grains which finally consume almost entire weld zone. It has been observed in various aluminum alloys including $1 \mathrm{xxx}$ [3-6], $2 \mathrm{xxx}$ [7-16], $5 \mathrm{xxx}$ [17-29], $6 \mathrm{xxx}$ [30-33], and $7 \mathrm{xxx}[11,34-41]$ series, as well as in magnesium alloys [42-45], some steels [46-49], and even metal-matrix composites [50,51], thus perhaps being an intrinsic characteristic of FSW.

In this context, it is important to point out that the thermal stability of friction-stir welds is sensitive to welding conditions. Specifically, a lowering of FSW temperature often decreases the onset temperature for the abnormal grain growth $[3,8-10,19,21,31,34,35]$.

Within the stir zone, the abnormal microstructural coarsening typically initiates either at the upper weld surface or at the weld root $[4,8,9$, $15,17,19-21,25-27,31,34-36,38,40,41,43,45,48,52,53]$. Also, the grain growth at the advancing side (AS) is often more pronounced than that at the retreating side (RS) $[8,25,27,30,36,38,43,48,52]$. These effects are sometimes attributed to the specific microstructures that evolved in these areas during FSW [20].

It is worth noting that the crystallographic aspects of the abnormal grain growth have attracted relatively low attention so far. In a few works, it has been found that at the early stage of the microstructural coarsening, the crystallographic orientations of the abnormal-growing grains are close to the simple-shear texture produced during FSW [16, 46]. On the other hand, the final texture evolved after the completion of the grain-growth process has been reported to be essentially altered with respect to the original FSW-induced texture [4,6,32]. Considering the contradictive character of the above results as well as the fundamental significance of the crystallographic measurements for elucidation of microstructural mechanisms, the texture analysis of the abnormal grain growth deserves more attention.

Very often $[8,18-21,23,34,35,51,54]$, the abnormal microstructural coarsening in friction-stir welded materials is explained in terms of the Humphreys cellular model $[55,56]$. According to this theory, the abnormal annealing behavior is attributed to a combined effect of drastic grain refinement and dissolution of second-phase particles both occurring during FSW. Alternative explanations for the catastrophic grain growth include inhomogeneous microstructure distribution within the stir zone $[20,31,40,48]$, precipitation of grain-boundary segregations $[47,49]$, and increased mobility of particular grain-boundaries $[6$,

\footnotetext{
* Corresponding author.

E-mail address: mironov@bsu.edu.ru (S. Mironov).
} 
44].

While significant efforts have been undertaken to investigate the abnormal annealing phenomena, an examination of the microstructureproperty relationship in the abnormal-coarse friction-stir welds attracts a relatively low interest. So far, the main emphasis in such studies has been paid to superplastic forming. As expected, the catastrophic microstructural coarsening was found to essentially degrade material ductility at elevated temperatures $[7,17,18]$. On the other hand, the influence of the abnormal grains on the mechanical performance of welds at ambient conditions is less clear.

As follows from the limited data available in scientific literature, the welds with abnormal grains usually exhibit relatively high strength during transverse tensile tests, with joint efficiency ranging from 75 to $100 \%[9,30,32,36,37]$. On the other hand, ductility of such welds has been reported to substantially scatter from very low magnitude $[9,32$, $36]$ to that comparable with the parent material characteristics [30,37]. Their failure has been found to occur either in the stir zone $[8,9,32,36]$ or in the base material region $[30,36]$. Due to the contradictive nature of the above results, the mechanism which governs the microstructure-property relationship in such welds is still uncertain.

The present work attempted to tie together FSW conditions, annealing behavior during post-weld treatment, and mechanical performance of welds. To provide a thorough insight into the material behavior, advanced characterization techniques were employed including electron backscatter diffraction (EBSD) and digital image correlation (DIC).

\section{Experimental}

The material used in the present investigation was a commercial 6061 aluminum alloy with measured chemical composition (wt.\%) of $0.88 \mathrm{Mg}, 0.66 \mathrm{Si}, 0.72 \mathrm{Fe}, 0.26 \mathrm{Cu}, 0.12 \mathrm{Mn}, 0.12 \mathrm{Cr}, 0.09 \mathrm{Zn}$, and balance $\mathrm{Al}$. This is a typical heat-treatable aluminum alloy, which is widely used in industry and whose FSW behavior is studied relatively well. The material was supplied as a hot-extruded bar. To produce a peak-hardened condition, the received material was subjected to the standard T6 tempering treatment, i.e., solutionized at $540{ }^{\circ} \mathrm{C}$ for $1 \mathrm{~h}$, water quenched, and then artificially aged at $160^{\circ} \mathrm{C}$ for $8 \mathrm{~h}$. The final material was characterized by a relatively coarse-grained structure elongated along the extrusion axis, a strong $<111\rangle+<100>$ fiber texture, and nano-scale $\beta^{/ /}$precipitates evenly distributed in grain interior (Supplementary Fig. S1). Further microstructural details have been described elsewhere [57]. This material condition was denoted as base material throughout the manuscript.

The 3-mm-thick sheets of the base material were friction-stir butt welded along the extrusion direction using a commercial AccurStir FSW machine. The welding tool was manufactured from tool steel and consisted of a concave-shaped shoulder with a diameter of $12.5 \mathrm{~mm}$ and an M5 cylindrical probe with a length of $2.7 \mathrm{~mm}$. To investigate material behavior in a wide range of welding conditions, FSW variables were systematically altered, as shown in Table 1 . This range was defined by the capability of the employed FSW machine as well as the formation of welding defects. In all cases, FSW was conducted under the plungedepth control mode, the tool tilting angle was $2.5^{\circ}$, and stainless steel was used as a backing plate. To differentiate different welds throughout this manuscript, the $\mathrm{N} \times \mathrm{V}$ code was employed, where $\mathrm{N}$ is the spindle rate $(\mathrm{rpm})$ and $\mathrm{V}$ is the tool feed rate $(\mathrm{mm} / \mathrm{min})$, as indicated in Table 1.

Table 1

Weld designation.

\begin{tabular}{llll}
\hline Spindle rate, rpm & \multicolumn{3}{l}{ Feed rate, $\mathrm{mm} / \mathrm{min}$} \\
\cline { 2 - 4 } & 125 & 380 & 760 \\
\hline 500 & $500-125$ & $500-380$ & - \\
750 & $750-125$ & $750-380$ & $750-760$ \\
1100 & $1100-125$ & $1100-380$ & $1100-760$ \\
\hline
\end{tabular}

The typical convention for FSW geometry was adopted, where WD is the welding direction, TD is the transverse direction, and ND is the normal direction of the welded sheets.

To record the weld thermal cycle, K-type thermocouples were placed to the heat-affected zone and at the stir zone border, as schematically shown in Supplementary Fig. S2. The peak magnitudes of the measured welding temperatures as a function of FSW conditions are shown in Table 2 .

In order to examine the thermal stability of the welded materials, the produced welds were subjected to the standard T6 tempering treatment, i.e., solutionized at $540{ }^{\circ} \mathrm{C}$ for $1 \mathrm{~h}$, water quenched, and then artificially aged at $160{ }^{\circ} \mathrm{C}$ for $8 \mathrm{~h}$.

Microstructural observations were primarily conducted with EBSD and were focused on transverse cross-section (TD $\times$ ND plane) of the welds. A suitable surface finish for examinations was prepared using conventional mechanical polishing technique followed by electropolishing in a solution of $25 \%$ nitric acid in methanol.

EBSD was performed using FEI Quanta 600 and FEI Quanta Nova NanoSEM 450 field-emission gun scanning electron microscopes (FEGSEMs) both equipped with a TSL OIM ${ }^{\mathrm{TM}}$ system and operated at an accelerated voltage of $30 \mathrm{kV}$. For microstructural analysis of the aswelded materials, relatively fine scan-step sizes of 0.5 or $1 \mu \mathrm{m}$ were used. For examination of the annealed welds, sample-scale EBSD maps were acquired. In this case, a relatively coarse scan step size of $5 \mu \mathrm{m}$ was employed. To minimize the possibility of misindexing errors during EBSD mapping, seven Kikuchi bands were analyzed for each diffraction pattern. To enhance the reliability of EBSD data, the fine grains comprising three or fewer pixels were automatically removed from the maps using a standard grain-dilation option of the EBSD software. Furthermore, to eliminate the spurious boundaries associated with orientation noise, a lower-limit misorientation cut-off of $2^{\circ}$ was applied. A $15^{\circ}$ criterion was employed to differentiate low-angle boundaries (LABs) from high-angle boundaries (HABs). The grain size was measured using the grain-reconstruction approach [58].

The mechanical behavior of the welds was examined using microhardness measurements and transverse tensile tests. Vickers microhardness profiles were acquired across the weld mid-thickness by applying a load of $200 \mathrm{~g}$ with a dwell time of $10 \mathrm{~s}$, and using a Wolpert 402 MVD microhardness tester. The tensile specimens were cut perpendicular to the welding direction and were centered along the weld centerline. The specimens had a gauge section of $35 \mathrm{~mm}$ in length and $6 \mathrm{~mm}$ in width and included all characteristic microstructural zones generated during FSW. The upper and bottom surfaces of the specimens were mechanically polished to achieve a uniform thickness and remove the kissing bond defect at the weld root. For a comparative purpose, appropriate tensile specimens were also machined from the base material. The tension tests to failure were conducted at ambient temperature and a constant cross-head velocity corresponding to a nominal strain rate of $10^{-3} \mathrm{~s}^{-1}$. An Instron 5882 universal testing machine was used for the tests. At least two tensile specimens were tested for each material condition.

To provide a quantitative insight into a relationship between the microstructure distribution within the welded materials and the tensile

Table 2

Effect of FSW conditions on the peak welding temperature.

\begin{tabular}{llll}
\hline \multirow{2}{*}{ Welds } & \multicolumn{2}{l}{ Peak welding temperature, ${ }^{\circ} \mathrm{C}$} \\
\cline { 2 - 4 } & Heat-affected zone & Upper section of stir zone & Stir zone nugget \\
\hline $500-125$ & 247 & 385 & 385 \\
$500-380$ & 226 & 369 & 369 \\
$750-125$ & 247 & 411 & 411 \\
$750-380$ & 244 & 373 & 373 \\
$750-760$ & 233 & 384 & 384 \\
$1100-125$ & 312 & 444 & 444 \\
$1100-380$ & 252 & 405 & 405 \\
$1100-760$ & 248 & 321 & 321 \\
\hline
\end{tabular}


behavior of the welds, DIC technique was employed. The in-plane distributions of Lagrangian strains were measured on all specimens' surfaces (i.e., both flat surfaces and both side surfaces) using a commercial Vic-3D system. For the measurements, a random ink pattern was applied to the surfaces of each specimen prior to the tension and two high-speed digital cameras were employed for image recording during the tests.

The fracture surfaces of the failed specimens were examined with FEI Quanta Nova NanoSEM 450 and FEI Quanta 200 FEG-SEMs.

\section{Results}

\subsection{Microstructure characterization}

Typical EBSD grain-boundary maps taken from the stir zones of various welds in the as-welded condition are shown in Fig. $1^{1}$. Relevant microstructural statistics derived from the maps are summarized in Table 3. In all cases, the evolved grain structures were dominated by fine nearly-equiaxed grains which contained a pronounced LAB substructure. Such microstructures are often observed in friction-stir welded aluminum alloys being usually attributed to the development of continuous recrystallization [e.g. 59-61]. Depending on particular welding conditions, the measured mean grain size ranged from 2 to $9 \mu \mathrm{m}$ whereas the measured HAB fraction varied from 62 to $81 \%$ (Table 3). As expected, a reduction of the spindle rate and/or an increase of the feed rate enhanced the grain-refinement effect in the stir zone. Specifically, the finest grain structure was observed in 500-380 weld whereas the coarsest one in 1100-125 weld (Fig. 1, Table 3).

The post-weld T6 treatment resulted in drastic microstructural coarsening (Fig. 2). Importantly, the grain-growth process was essentially influenced by the FSW conditions. Particularly, the coarsest grain structure was found in the weld produced at the combination of the highest spindle rate and the lowest feed rate (i.e., the 1100-125 weld). On the other hand, the weld obtained at the lowest spindle rate, but the highest feed rate was characterized by relatively small grain size (i.e., the 500-380 weld). Therefore, a lowering of the FSW heat input provided the formation of a relatively fine-grained structure during postweld annealing treatment.

It is also worth noting that microstructural coarsening on the AS of the stir zone was more pronounced than that on the RS (Fig. 2). This observation agreed well with a number of previous reports in the scientific literature [8,25,27,30,36,38,43,48,52].

Of particular interest was a development of the fine-grained layer near stir-zone edges of the annealed welds (Fig. 2). This effect was most prominent in the low-heat-input welds (specifically, in the 500-380 weld). It is also remarkable that the fine-grained layer on the RS was wider than that on the AS (Fig. 2). A possible origin of such microstructural regions is discussed in Section 4.1.2.

\subsection{Mechanical tests}

To evaluate the microstructure-strength relationship in the welded material, microhardness profiles were measured across the weld midthickness. The typical examples are shown in Fig. 3 whereas the entire data set is provided in the Supplementary Fig. S4. As expected, FSW resulted in substantial material softening. As shown in previous work [62], this effect was associated with coarsening and/or partial dissolution of strengthening precipitates of $\beta$ // phase. Also quite expectedly, the post-weld T6 treatment promoted complete recovery of material strength, presumably due to re-precipitation of the secondary-phase dispersoids.

To shed more light on the mechanical behavior of the annealed welds, transverse tensile tests were conducted. Typical deformation

\footnotetext{
${ }^{1}$ Low-magnification optical images of the welds are shown in the Supplementary Fig. S3.
}

diagrams are presented in Fig. 4a, while the entire data set is summarized in the Supplementary Fig. S5. The relevant mechanical characteristics are shown in Table 4. Predictably, the yield strength of the heattreated welds was broadly similar to that of the base material. An important characteristic of the welded material was relatively high strain hardening (Fig. 4a). A similar effect has been reported in the scientific literature $[11,30]$. Despite the relatively high strain hardening, however, the welds exhibited relatively low ductility (Fig. 4a, Table 5).

Attempting to ascertain this contradictive result, deformation relief was examined. The typical appearance of the failed tensile specimens is illustrated in Fig. 4b; the entire data wet is provided in Supplementary Fig. S6. In all cases, strain distribution was inhomogeneous throughout the welded samples being preferentially concentrated either in the base material region and/or near the stir zone edge (i.e., virtually, in the finegrained layer mentioned in the previous section). On the other hand, the stir zone exhibited only poorly developed relief. The heterogeneous character of the strain distribution explains well the limited ductility observed in the welds.

A remarkable issue was also a failure location of the welded specimens. In most cases, those failed either in the base material zone or at the stir zone edge (i.e., in locations of the preferential strain concentration) thus exhibiting entirely expectable behavior (Fig. 4b, Table 5). A notable exception was only the highest-heat-input 1100-125 welds which always fractured at the stir zone center (Table 5).

\subsection{Digital-image-correlation measurements}

In order to provide more fundamental insight into the tensile behavior of the annealed welds, the digital image correlation technique was applied. The typical obtained results are shown in Figs. 5 and 6; the remaining data are provided in the Supplementary Figs. S7-S14.

In most cases, an early stage of the tensile elongation was characterized by nearly-uniform strain distribution throughout the welded specimens (Fig. 5). This agreed well with microhardness measurements (Fig. 3). Then, however, material flow in the stir zone tended to stagnate (Fig. 5).

At this stage, plastic deformation tended to concentrate preferentially either in the base material zone or at the stir zone edge (Fig. 5). Importantly, the plastic strain in the latter case always clustered on the retreating side, i.e., a location where the fine-grained layer was most pronounced. The final failure occurred in one of the two above locations (Fig. 5).

The tensile behavior of the highest-heat-input 1100-125 weld was somewhat specific (Fig. 6). In this case, a preferential strain concentration was observed within the stir zone. The progressive strain development in this area finally led to the weld failure.

\subsection{Fracture analysis}

Attempting to shed more light on the unusual tensile performance of the 1100-125 weld, its fracture behavior was compared with those of other welded specimens. The typical fracture surfaces are shown in Figs. 7 and 8, respectively.

As mentioned in two previous sections, most of the welds failed in either the base material zone or the fine-grained region. In all these cases, the fracture surface exhibited a typical dimple appearance ${ }^{2}$ (Fig. 7) thus evidencing a ductile mechanism of the fracture.

In contrast, the highest-heat-input 1100-125 welds always failed in the stir zone. In this instance, the fracture surface was characterized by

\footnotetext{
${ }^{2}$ The fracture surfaces of the welds failed in the base material zone and those fractured in the fine-grained region were found to be broadly similar to each other. For the sake of simplicity, therefore, only the former one was included to the manuscript, whereas the latter one was provided in the Supplementary Fig. S16.
} 

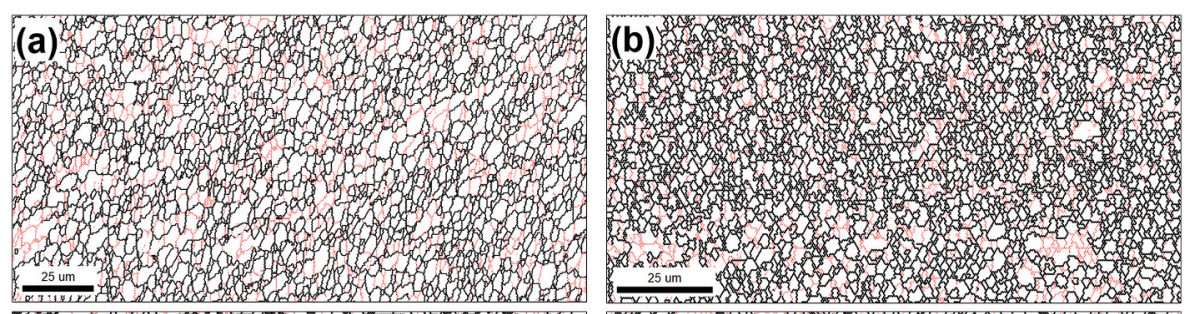

$$
\underbrace{\text { TD }} \overbrace{}^{\mathrm{WD}}
$$
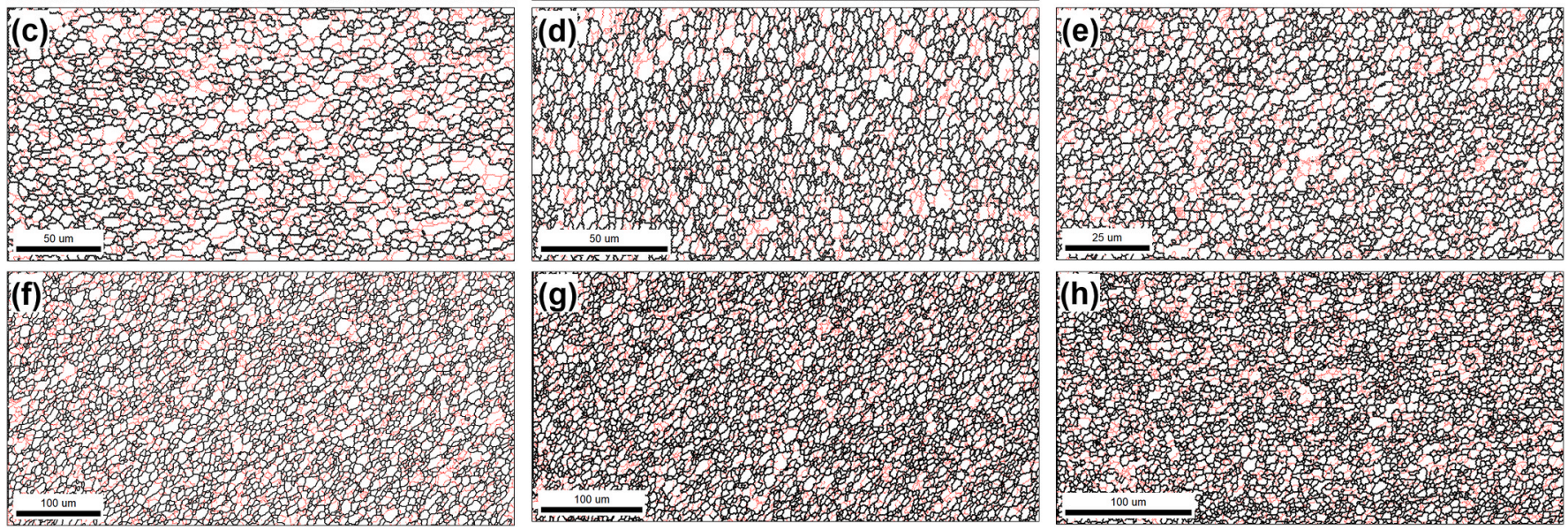

Fig. 1. Selected portions of EBSD grain-boundary maps showing stir-zone microstructures in the as-welded condition of 500-125 weld (a), 500-380 weld (b), 750-125 weld (c), 750-380 weld (d), 750-760 weld (e), 1100-125 weld (f), 1100-380 weld (g), and 1100-760 weld (h). The reference frame for all figures is shown in the top right corner; WD, ND, and TD refer to the welding direction, normal direction, and transverse direction, respectively. In all cases, LABs and HABs are depicted as red and black lines, respectively. (For interpretation of the references to color in this figure legend, the reader is referred to the Web version of this article.)

Table 3

Microstructural characteristics of the stir-zone material in various welds.

\begin{tabular}{llllll}
\hline \multirow{2}{*}{ Weld } & \multicolumn{2}{l}{ Mean grain size, $\mu \mathrm{m}$} & & \multicolumn{2}{l}{ HAB fraction, \% } \\
\cline { 2 - 3 } \cline { 5 - 6 } \cline { 5 - 6 } & Top & Nugget & & Top & Nugget \\
\hline $500-125$ & $4.1 \pm 1.6$ & $3.9 \pm 1.6$ & & 67 & 71 \\
$500-380$ & $2.3 \pm 0.7$ & $2.5 \pm 0.6$ & & 74 & 81 \\
$750-125$ & $6.6 \pm 2.7$ & $5.6 \pm 2.2$ & & 62 & 62 \\
$750-380$ & $5.8 \pm 1.7$ & $3.3 \pm 0.9$ & & 68 & 77 \\
$750-760$ & $3.2 \pm 1.0$ & $2.6 \pm 0.8$ & & 66 & 73 \\
$1100-125$ & $8.7 \pm 3.6$ & $8.5 \pm 3.0$ & & 65 & 68 \\
$1100-380$ & $6.8 \pm 2.3$ & $6.3 \pm 1.9$ & 66 & 71 \\
$1100-760$ & $5.7 \pm 2.3$ & $5.0 \pm 1.6$ & 64 & 72 \\
\hline
\end{tabular}

very poorly developed topography (Fig. 8) thereby indicating a nearlybrittle failure mechanism.

\section{Discussion}

\subsection{Microstructure evolution during solutionizing annealing}

As shown in Fig. 2, solutionizing annealing resulted in drastic microstructural changes in welds. In the following sections, the underlying microstructural mechanisms are considered in various FSWinduced microstructural zones, i.e., the stir zone, thermo-mechanically affected zone, and heat-affected zone.

\subsubsection{Stir zone}

EBSD maps taken from the stir-zone center of 500-380 and 1100-125 welds are shown in Fig. 9a and b, respectively. These two represent the lowest- and highest heat-input welds, respectively, and thus outline the entire range of the studied FSW conditions. In all cases, a very broad grain-size distribution as well as the presence of "island" grains (several examples are arrowed) indicated an abnormal nature of the grain growth process.
It is important to emphasize that the low-heat-input welds were characterized by relatively fine-grained structure (Figs. 2 and 9). This implies a more or less competitive character of the microstructural coarsening process in these cases. It seems, therefore, that a lowering of the FSW heat input tends to suppress the abnormal grain growth.

Attempting to provide fundamental insight into the grain growth process, the concomitant textural changes were investigated. To this end, the textures produced in the fully-annealed specimens were compared with those in the as-welded condition, as shown in Fig. 10. It is seen that the textures resulted from the abnormal grain growth were not random. Instead, the FSW-induced $B / \bar{B}\{112\}<110>$ simple-shear orientations experienced a rotation of $20-25^{\circ}$ around $<111>$ and $<110>$ axes.

A similar phenomenon has been observed in a number of previous studies $[4,6,32,33]$ being sometimes explained in the terms of "orientation growth" theory $[6,33]$. This model is based on a presumption that some grain-boundaries in face-centered cubic metals are characterized by relatively high migration mobility; hence, the rapid migration of such boundaries may provide a preference in growth by some grains, thus resulting in a texture rotation [63].

\subsubsection{Thermo-mechanically affected zone}

In friction-stir welds, the stir zone is known to be typically outlined by the so-called thermo-mechanically affected zone. In this microstructural region, the welded material undergoes relatively small strains at comparatively low temperatures which are not sufficient for dynamic recrystallization. If so, this material may contain a relatively high dislocation density. Hence, its subsequent high-temperature annealing may result in static recrystallization.

In this context, it is worth noting that the stir zones of the fullyannealed welds studied in the present work were often outlined by a fine-grained layer (Fig. 2). Remarkably, this layer was most pronounced on the retreating side, thus resembling the characteristics of a typical thermo-mechanically affecting zone. The magnified images of the 

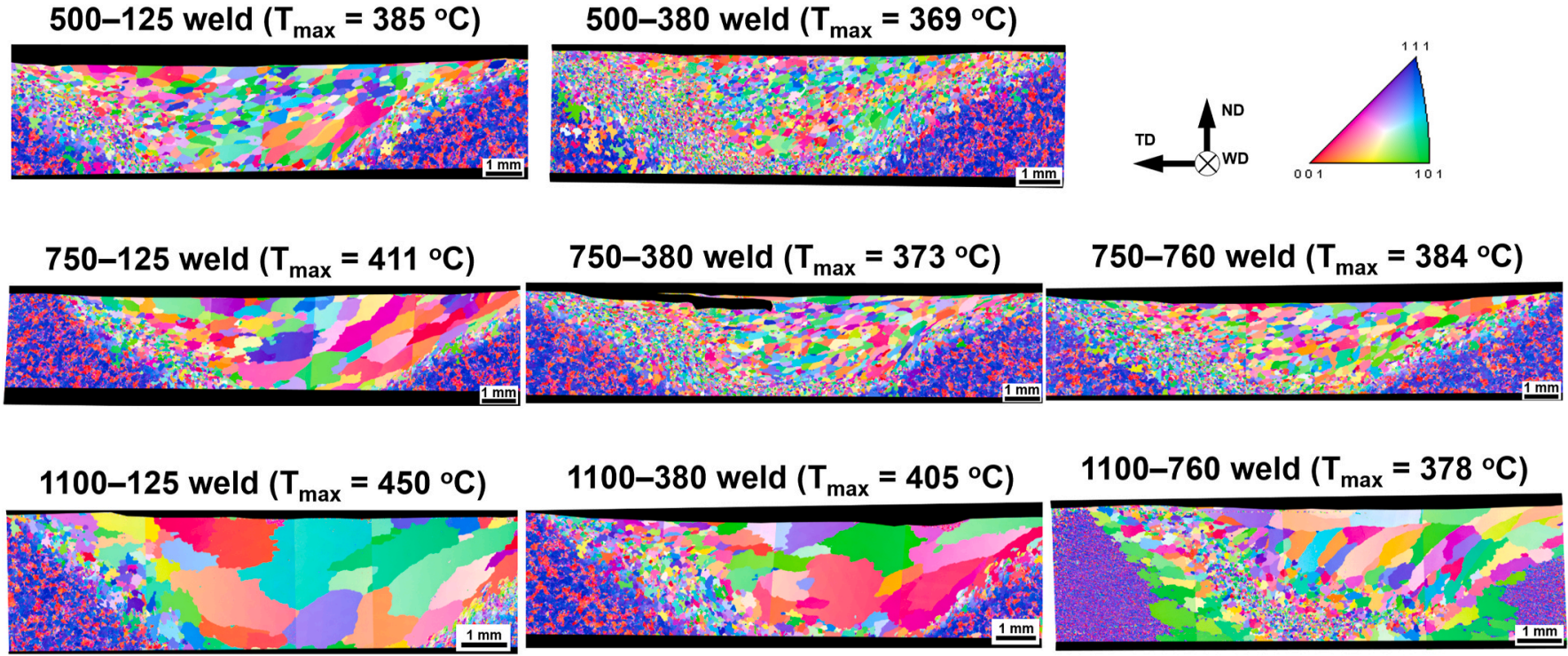

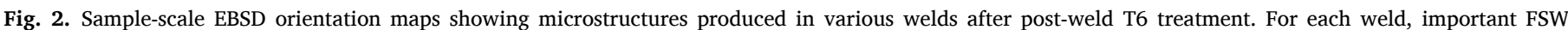
conditions (i.e., spindle rate, feed rate and the peak welding temperature) are indicated above the maps. In the maps, grains are colored according to their crystallographic orientations relative to welding direction (the color code triangle is given in the top right corner). WD, ND, and TD refer to the welding direction, normal direction, and transverse direction, respectively. In each case, the retreating size (RS) is left and the advancing side (AS) is right. (For interpretation of the references to color in this figure legend, the reader is referred to the Web version of this article.)
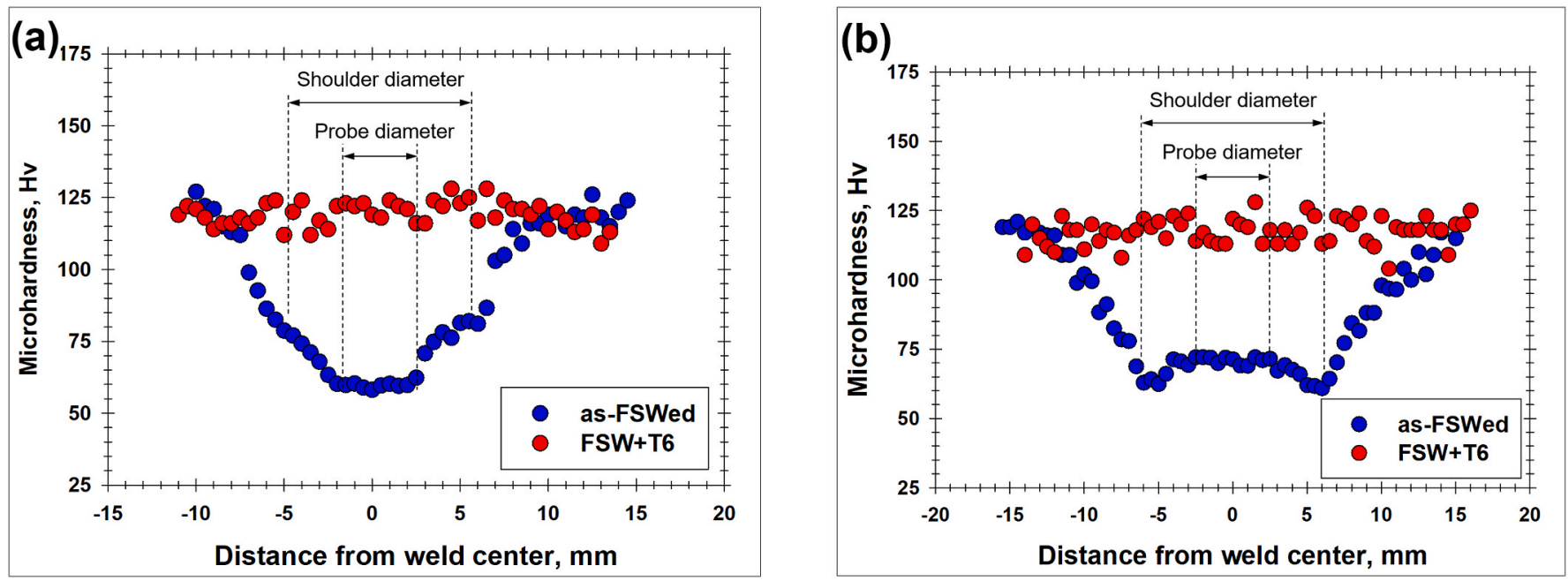

Fig. 3. The typical microhardness profile showing the effect of the post-weld $\mathrm{T} 6$ tempering treatment on the strength of low-heat-input welds (a), and high-heatinput welds (b). In all cases, the retreating size (RS) is on the left, and the advancing side (AS) is on the right. In (a) and (b), the data were taken from 500-380 weld and 1100-125 weld, respectively.

microstructures typically observed at the edge of the stir zone are shown in Fig. 11. It is seen the fine-grained layer was dominated by nearlyequiaxed grains which contained almost no LAB-substructure, thereby being broadly similar to a typical recrystallized microstructure.

To provide further insight into the origin of the fine-grained region, appropriate textural analysis was undertaken. As the FSW-induced strain in the thermo-mechanically affected zone is typically low, the preferential crystallographic orientation in this region should be close to the base material texture. A comparison of the textures measured in the fine-grained regions of two different welds with that of the base material is shown in Fig. 12. In all cases, the preferential crystallographic orientations were close to $<111>/ /$ WD fiber texture, i.e., all these textures appear to be qualitatively similar. The retention of the base material orientation in the fine-grained layer suggests that the latter material experienced no stirring during FSW. If so, it fits the definition of the thermo-mechanically affected zone. On the other hand, a very low texture intensity measured in the fine-grained layer (Fig. 12b and c) agrees well with the recrystallization origin of this microstructural region.

A remarkable characteristic of the texture measured in the finegrained layer was also a development of the weak $<110>$ component (Fig. 12c). A possible genesis of this orientation is discussed in the following section.

\subsubsection{Heat-affected zone}

In friction-stirred materials, the thermo-mechanically affected zone is normally confined by a heat-affected zone. In heat-treatable aluminum alloys (including that studied in the present work), the microstructure evolution in this area during FSW is usually dominated by a coarsening of the constituent second-phase particles [64]. This 

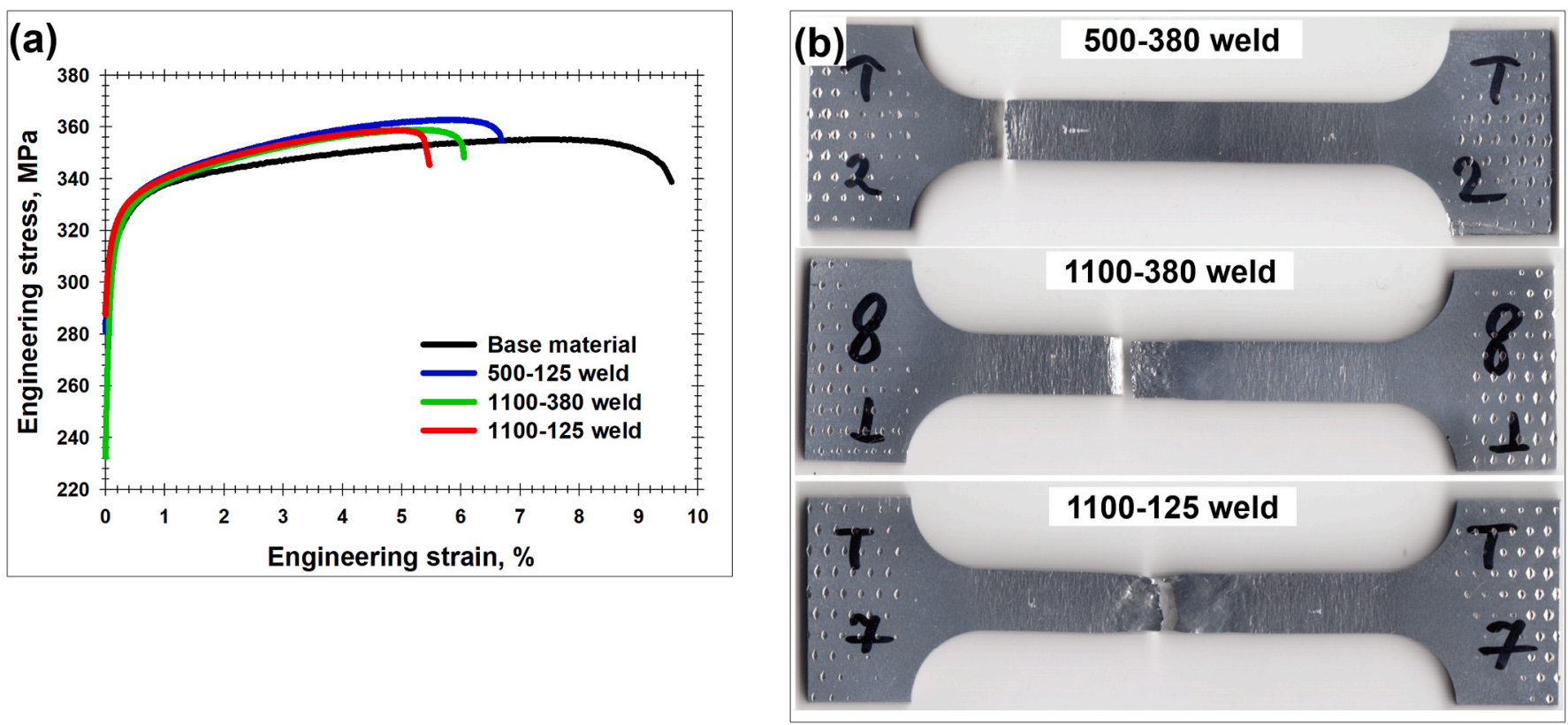

Fig. 4. (a) Typical deformation diagrams and (b) typical appearance of failed specimens illustrating transverse tensile behavior of T6-tempered welds. In (b), the retreating side is left, and the advancing side is right. See Section 3.2 for details.

Table 4

Mechanical properties of T6-tempered welds.

\begin{tabular}{llll}
\hline Weld & $\begin{array}{l}\text { Yield strength, } \\
\text { MPa }\end{array}$ & $\begin{array}{l}\text { Ultimate tensile } \\
\text { strength, MPa }\end{array}$ & $\begin{array}{l}\text { Elongation to } \\
\text { failure, \% }\end{array}$ \\
\hline $500-125$ & $305 \pm 2$ & $362 \pm 2$ & $6.7 \pm 0.6$ \\
$500-380$ & $290 \pm 0$ & $357 \pm 2$ & $6.6 \pm 0.9$ \\
$750-125$ & $300 \pm 7$ & $362 \pm 4$ & $7.3 \pm 2.1$ \\
$750-380$ & $305 \pm 9$ & $356 \pm 7$ & $6.3 \pm 2.0$ \\
$750-760$ & $322 \pm 6$ & $368 \pm 8$ & $7.7 \pm 0.2$ \\
$1100-125$ & $305 \pm 13$ & $357 \pm 3$ & $5.7 \pm 0.6$ \\
$1100-380$ & $306 \pm 3$ & $363 \pm 4$ & $6.7 \pm 0.6$ \\
$1100-760$ & $301 \pm 4$ & $365 \pm 4$ & $7.5 \pm 0.7$ \\
Base & $305 \pm 1$ & $355 \pm 3$ & $10.0 \pm 0.8$ \\
material & & & \\
\hline
\end{tabular}

Note: Error shows standard deviation.

Table 5

Effect of welding temperature on fracture location.

\begin{tabular}{lllll}
\hline $\begin{array}{l}\text { Peak welding } \\
\text { temperature, }{ }^{\circ} \mathrm{C}\end{array}$ & $\begin{array}{l}\text { Weld } \\
\text { condition }\end{array}$ & \multicolumn{2}{l}{ Failure location } \\
\cline { 3 - 5 } & & $\begin{array}{l}\text { Base } \\
\text { material }\end{array}$ & $\begin{array}{l}\text { Stir zone } \\
\text { edge }\end{array}$ & Stir zone \\
\hline 369 & $500-380$ & 2 samples & 1 sample & 0 \\
373 & $750-380$ & 2 samples & 0 & 1 sample \\
& & & & (defect) \\
378 & $1100-760$ & 0 & 2 samples & 1 sample \\
384 & $750-760$ & 1 sample & 1 sample & 0 \\
385 & $500-125$ & 2 samples & 1 sample & 0 \\
405 & $1100-380$ & 1 sample & 2 samples & 0 \\
411 & $750-125$ & 2 samples & 1 sample & 0 \\
450 & $1100-125$ & 0 & 0 & 3 samples \\
\hline
\end{tabular}

process reduces the particle pinning ability and thus degrades the thermal stability of the matrix material. In this context, the abnormal grain growth observed at the outer edge of the fine-grained layer (Fig. 11) appears to indicate that this microstructural region was the heat-affected zone.

Attempting to get insight into the microstructural behavior in this area, crystallographic orientations of the abnormal-coarse grains were measured, as shown in Fig. 13. It is seen that the abnormal grain growth resulted in a distinct $<110>/ /$ WD fiber texture.

A transformation from the base-material texture $<111>/ /$ WD into the $<110>/ /$ WD orientation in the heat-affected zone requires $\sim 35^{\circ}<110>$ rotation. This may be achieved via preferential migration of $\sim 35^{\circ}<110>$ boundaries. If so, the microstructural evolution in the heat-affected zone seems to be broadly similar to that in the stir zone. In both cases, the abnormal grain growth appears to be governed by the orientation-growth mechanism being associated with increased mobility of $\sim 25-35^{\circ}<110>$ boundaries. To validate this assumption, however, the direct misorientation measurements at an early stage of microstructural coarsening are required.

\subsubsection{The orientation growth mechanism}

The orientation growth theory is usually used for the analysis of recrystallization processes, for instance, a development of the recrystallization texture [63]. However, as the orientation growth mechanism involves a rapid migration of particular grain boundaries, it should result in selective growth of specific grains, i.e. virtually, in the abnormal grain growth. From this viewpoint, the orientation growth theory seems to be plausible for the explanation of the catastrophic microstructural coarsening observed in the present study.

Importantly, the activation of the orientation growth mechanism is usually associated with preferential migration of "special" grain boundaries which have a relatively high density of coincidence sites. In face-centered cubic metals (including aluminum alloys), those include $\Sigma 7\left(38.2^{\circ}<111>\right), \Sigma 13 \mathrm{a}\left(22.6^{\circ}<100>\right), \Sigma 13 \mathrm{~b}\left(27.8^{\circ}<111>\right)$, and $\Sigma 17$ $\left(28.1^{\circ}<100>\right)$ [63]. In the current study, the $25-35^{\circ}<110>$ boundaries, which have been deduced to be highly mobile, were rather close to $\Sigma 9$, i. e., $38.9^{\circ}<110>^{3}$. To the best of the authors' knowledge, the enhanced migration mobility of such boundaries has never been reported before. Therefore, the results obtained in the present work require further verification.

\footnotetext{
${ }^{3}$ Considering the relatively large orientation spread of the measured textures (Figs. 10 and 13), the accuracy of the texture-derived misorientations is low. Hence, the deduced $25-35^{\circ}<110>$ misorientations may virtually represent the ideal $\Sigma 9$ one.
} 


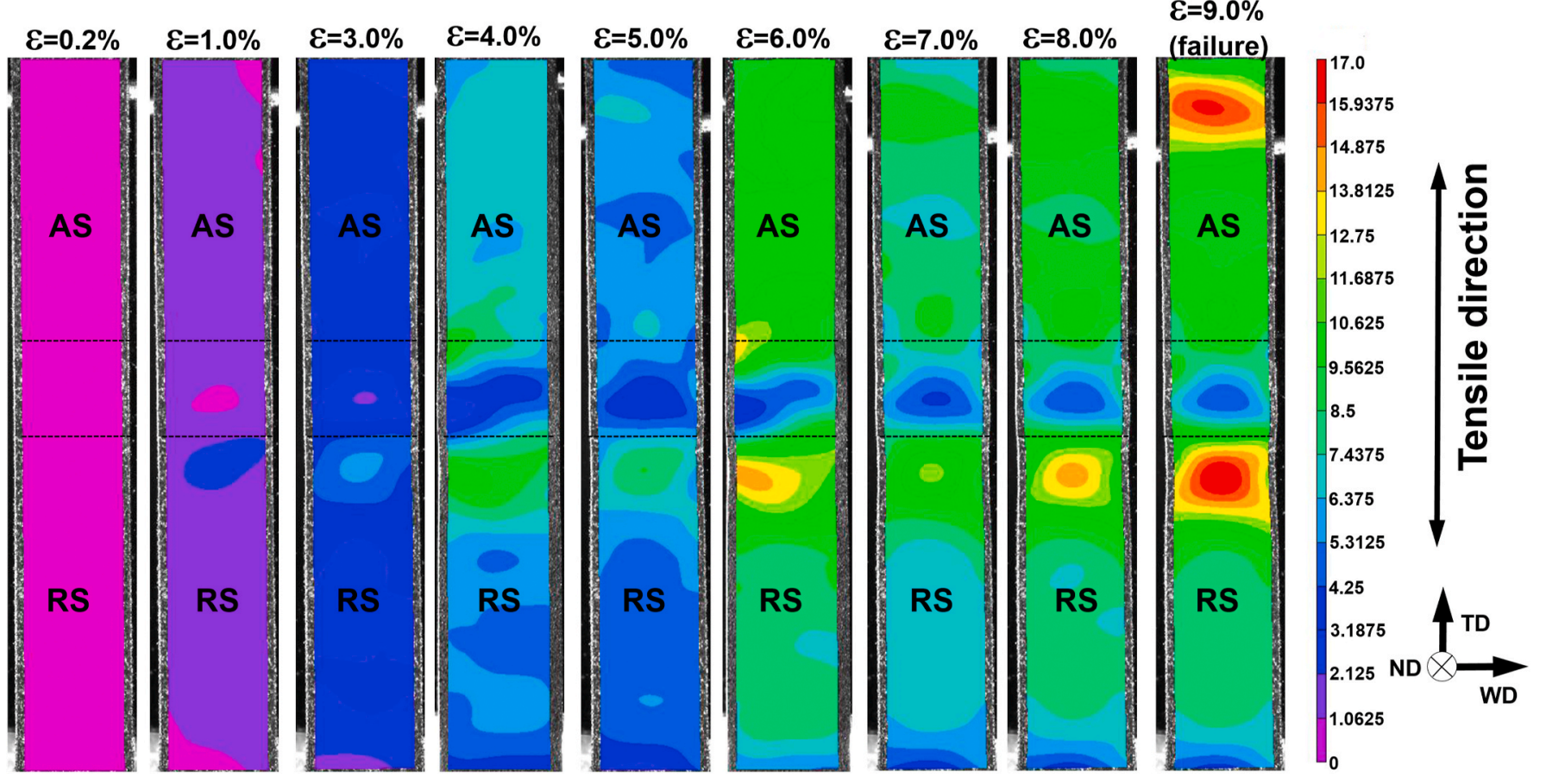

Fig. 5. One of the typical distributions of local longitudinal strains evolved during the transverse tensile test of T6-tempered welds. Case (a): the final failure occurred in either the base material zone or the fine-grained region. The global tensile elongation is indicated above the particular distribution. Dotted lines show probe diameter. AS and RS abbreviate the advancing side and the retreating side, respectively. Note: The data were taken from 750-125 weld. See Section 3.2 for details.
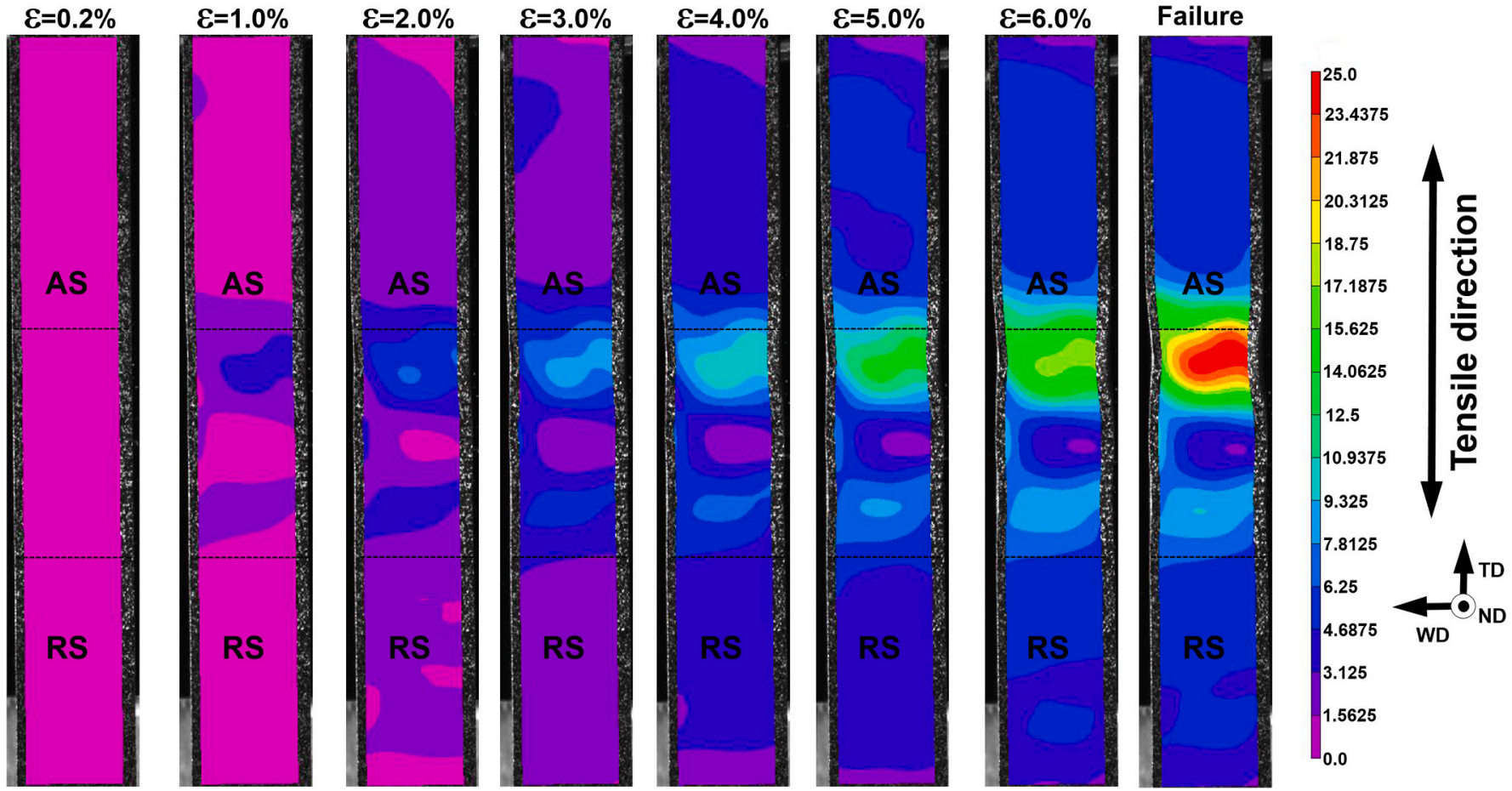

Fig. 6. One of the typical distributions of local longitudinal strains evolved during the transverse tensile test of T6-tempered welds. Case (b): the final failure occurred in the stir zone. The global tensile elongation is indicated above the particular distribution. Dotted lines show shoulder diameter. AS and RS abbreviate the advancing side and the retreating side, respectively. Note: The data were taken from 1100-125 weld. See Section 3.2 for details.

\subsubsection{Possible influence of second-phase particles}

One of the key findings of the present work is the revealed inhibition of the abnormal grain growth in the low-heat-input welds (Fig. 2). To ascertain this important result, it is necessary to realize that the material studied in the present work (i.e., 6061 aluminum alloy) was a heat- treatable alloy. Hence, its annealing behavior may be influenced by second-phase particles.

As shown in the previous work [62], a reduction of the heat input during FSW of this alloy may result in a transition from the particle dissolution to the particle coarsening in the stir zone. According to Zuiko 

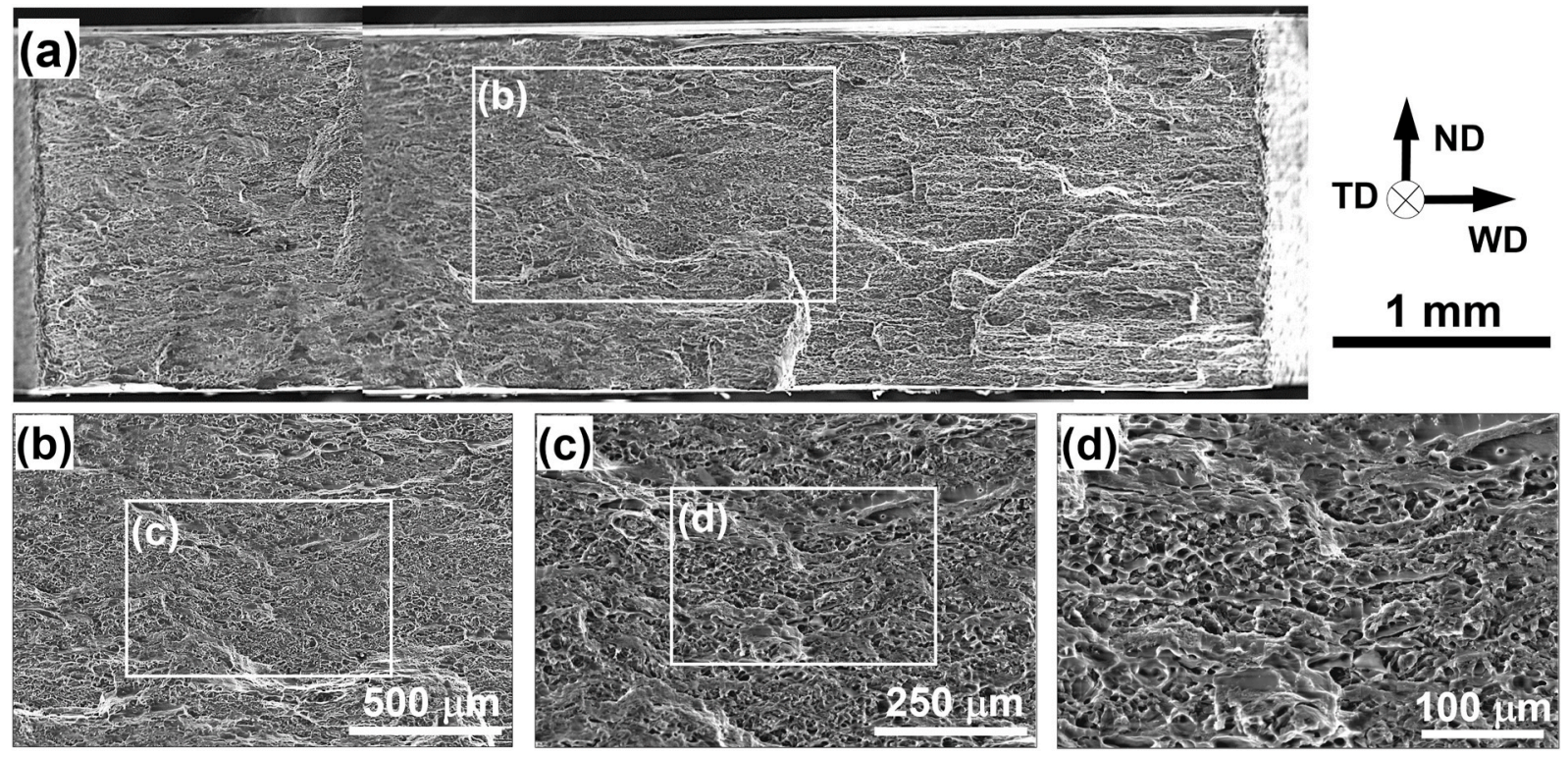

Fig. 7. The typical fracture surface of the welds failed in the base material zone (a) with selected areas shown at higher magnifications in (b) to (d). Note: The SEM micrographs were taken from $750-125$ weld.
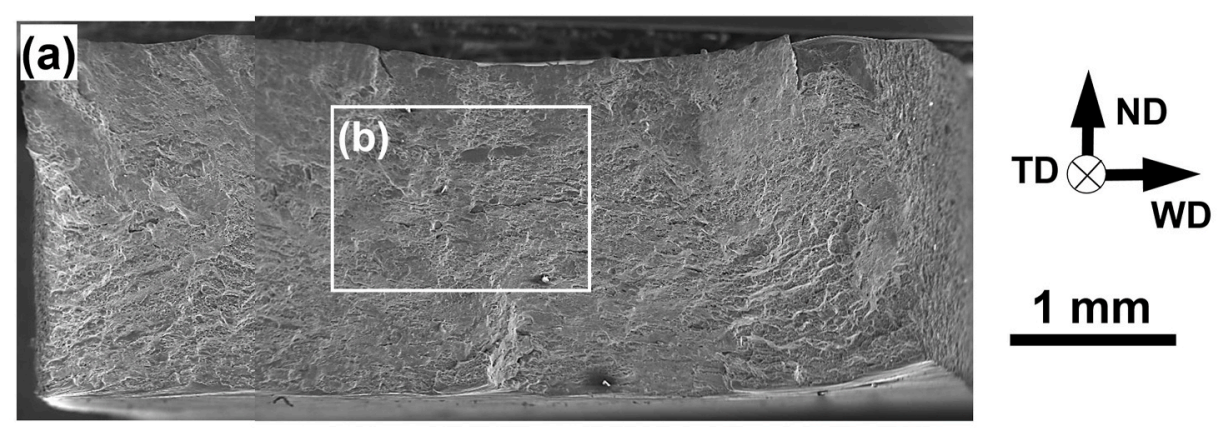

\section{$1 \mathrm{~mm}$}
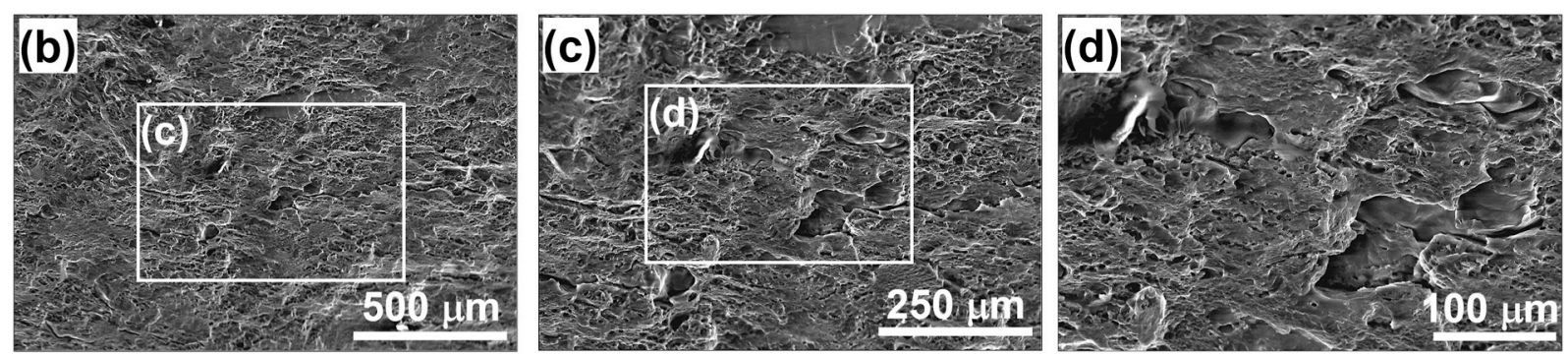

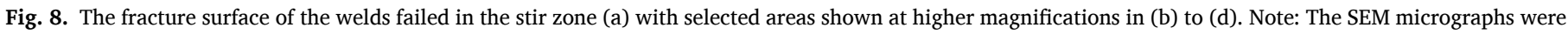
taken from 1100-125 weld.

et al. [65], this transition may principally affect the grain growth mechanism during post-weld T6 treatment. Specifically, in the high-heat-input welds, the dissolved dispersods tend to precipitate back during heating of the welded material up to the solutionizing temperature. As the freshly-nucleated particles are small in size, they exert a relatively high Zener pressure and thus may provide the activation of the abnormal grain growth mechanism. In the low-heat-input welds, in contrast, no particle re-precipitation occurs, but the retained precipitates continue to coarsen. This reduces the particle Zener force and thus may shift the annealing behavior towards the normal grain growth mechanism.

Therefore, it is possible that the inhibition of the abnormal grain growth in the low-heat-input welds observed in the present study was associated with the retention of the second-phase particles during FSW. It should be emphasized, however, that the above theory is still excessively speculative and thus warrants thorough experimental verification.

From the above considerations, it is likely that the microstructural coarsening studied in the present work was influenced by two factors (at least!), i.e., the preferential migration of particular grain boundaries and the second-phase particles. However, the interrelation between these two mechanisms and their mutual contribution to the grain growth process is completely unclear. Obviously, more research is needed in this area.

\subsection{Microstructure-property relationship}

The nearly-uniform microhardness profiles, which are similar to those seen in Fig. 3, are often found in the T6-tempered welds. They are usually attributed to the homogeneous precipitation of the second-phase dispersoids during the aging step of the post-weld heat treatment. 

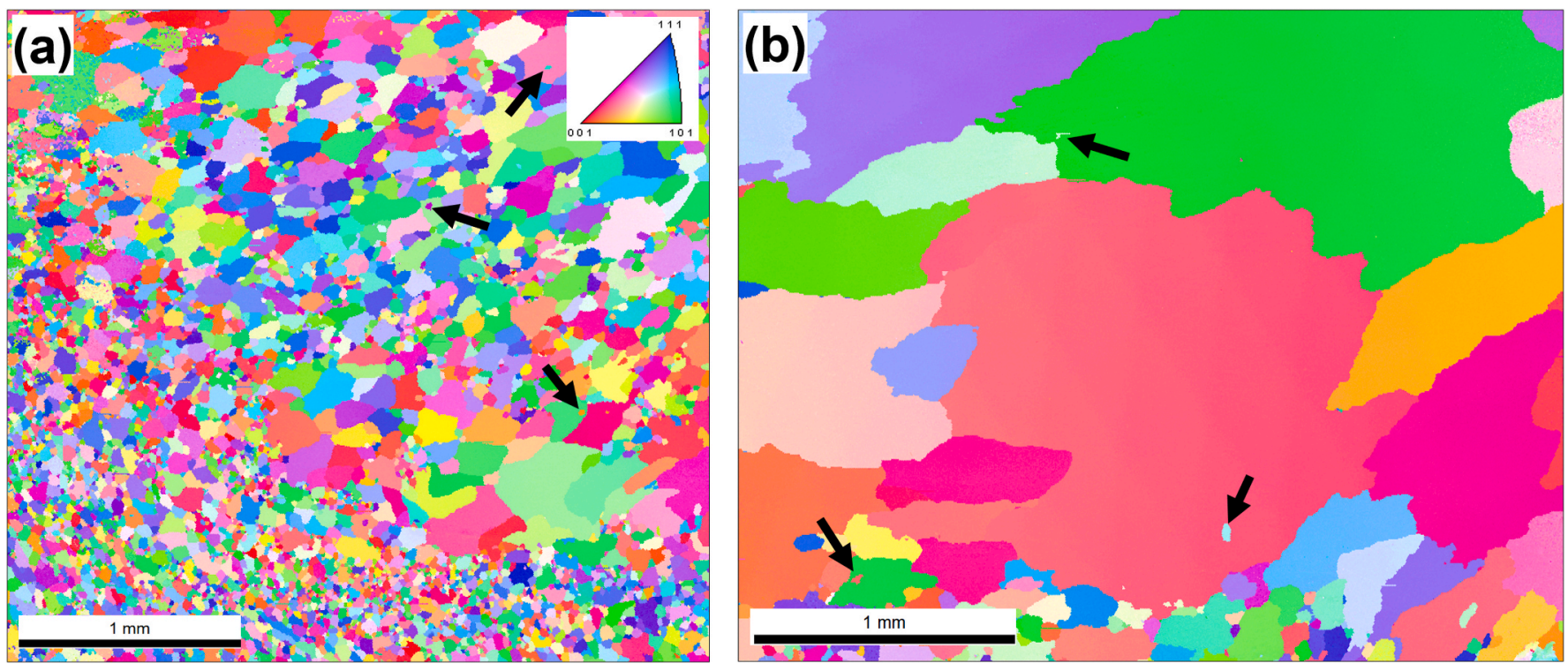

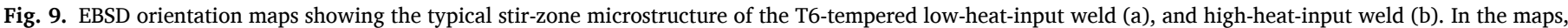

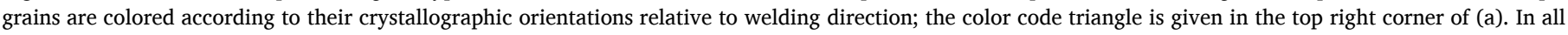

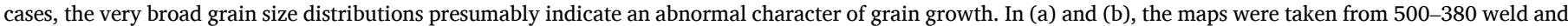

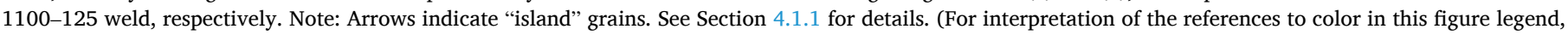
the reader is referred to the Web version of this article.)
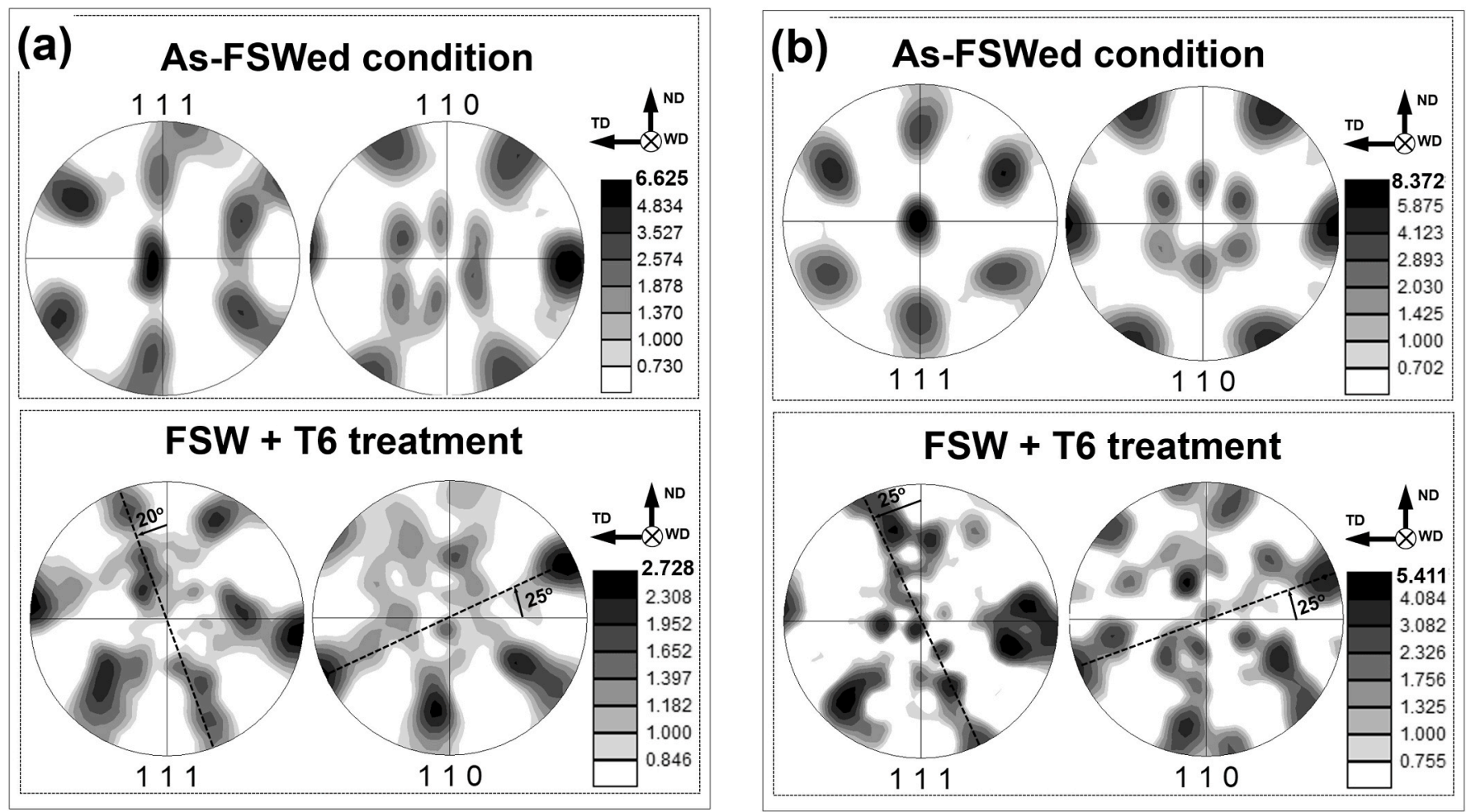

Fig. 10. 111 and 110 pole figures showing an effect of the abnormal grain growth occurring during $\mathrm{T} 6$ tempering treatment on crystallographic texture in the stir zone of (a) 500-380 weld (i.e., a typical low-heat-input weld), or 1100-125 weld (i.e., a typical high-heat-input weld). In all cases, the FSW-induced $B / \bar{B}\{112\}<$ $110>$ simple shear texture experienced a rotation of $\sim 20-25^{\circ}$ around $<111>$ and $<110>$ axes. WD, TD, and ND define welding direction, transverse direction, and normal direction, respectively.

Hence, the $100 \%$ joint efficiency for the yield strength revealed in all welding conditions studied in the present work (Table 4) was likely also associated with the secondary particles. In other words, the precipitates presumably played a dominant role in the mechanical behavior of welds at relatively low plastic strains. On the other hand, the observed variation of the weld ductility (Table 4) is hard to explain in terms of the second-phase particles. In the following two sections, the key issues in the microstructure-ductility relationship are discussed. 

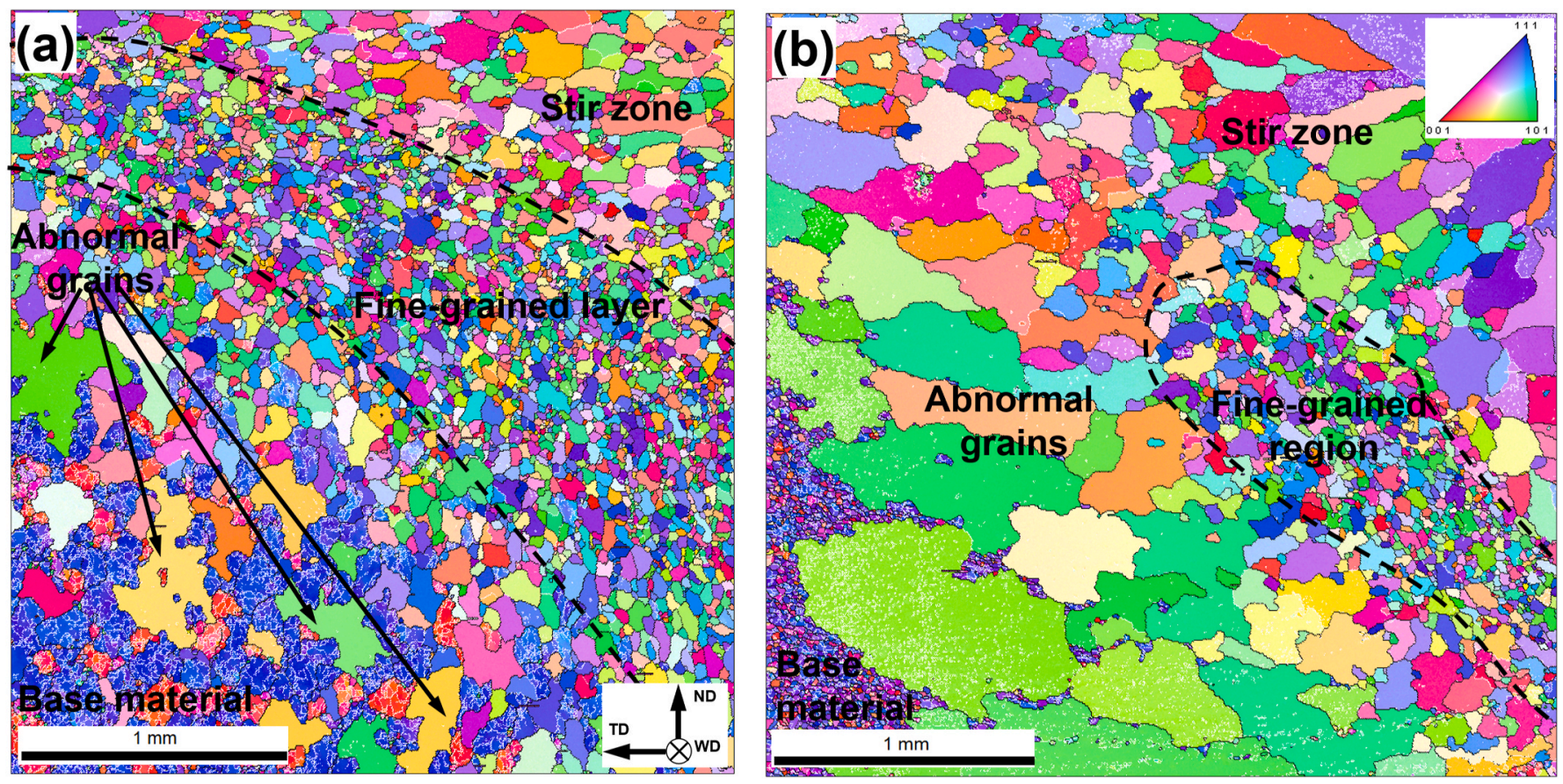

Fig. 11. EBSD orientation maps showing typical microstructures evolved at the edge of the stir zone of T6-tempered welds: (a) 500-380 weld and (b) 1100-760 weld. In all cases, grains are colored according to their crystallographic orientations relative to the welding direction (the color code triangle is shown in the top right corner of (a)); LABs and HABs are depicted as white and black lines, respectively. In both cases, the EBSD maps were taken from the retreating side. WD, TD and ND are welding direction, transverse direction, and normal direction, respectively. See Sections 4.1.2 and 4.1.3 for details. (For interpretation of the references to color in this figure legend, the reader is referred to the Web version of this article.)

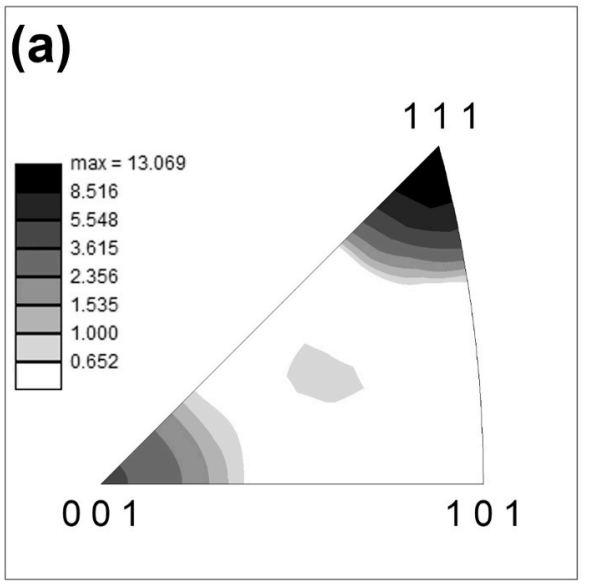

\section{(b)}

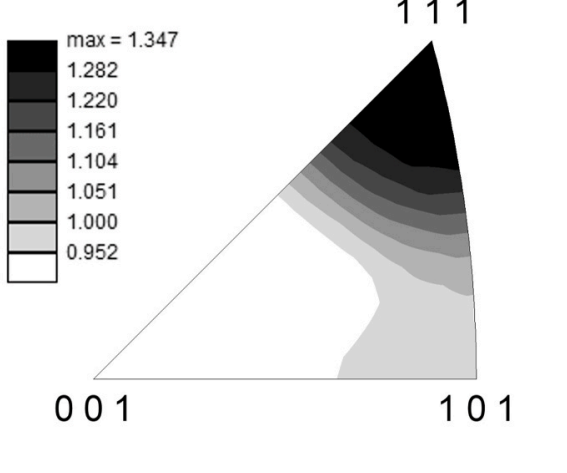

(c)

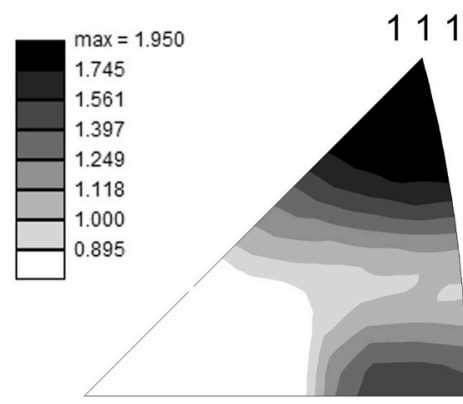

001

Fig. 12. Inverse-pole figures showing the base material texture (a) in comparison with the texture measured in the fine-grained region of 500-380 weld (b) and 1100-760 weld (c). In all cases, crystallographic orientations are given relative to the extrusion/welding direction. See Section 4.1.2 for details.

\subsubsection{Inhomogeneous microstructure distribution}

As shown in Section 4.1, the sharp microstructural gradient inherent to the FSW process results in an essential variation of the annealing phenomena during subsequent heat-treatment. Specifically, the material in the stir zone and/or the heat-affected zone experiences the abnormal grain growth whereas that in the thermo-mechanical affected zone undergoes the static recrystallization. Accordingly, the microstructure of the fully-annealed welds appears to be intrinsically inhomogeneous, and even elimination of the abnormal grain growth in the stir zone via lowering of the FSW heat input (as discussed in Section 4.1.1) unlikely can overcome this problem.

In this context, it is worth noting that the tensile behavior of the welds was characterized by relatively high strain hardening (Fig. 4a). It is important to emphasize that the work hardening ability is known to increase with microstructural coarsening [66]. This effect is attributed to the reduction of the density of geometrically-necessary dislocations [67] and the concomitant retardation of the formation of the dislocation cell structure [66]. It is likely, therefore, that the observed suppression of the tensile strain in the stir zone (Fig. 5) originated from the relatively high strain-hardening ability of the abnormal-coarse-grained material. Hence, the inhomogeneous distribution of the tensile strain and relatively low weld ductility (Fig. 4a and Table 4) were also associated with the abnormal-coarse grains.

This conception explains the preferential concentration of the tensile strain (and subsequent failure) in relatively fine-grained either the basematerial zone or the thermo-mechanically affected zone (Figs. 4b and 5, and Table 5). Remarkably, as the latter microstructural region is usually most pronounced on the RS, the tensile failure also occurs on this side. 

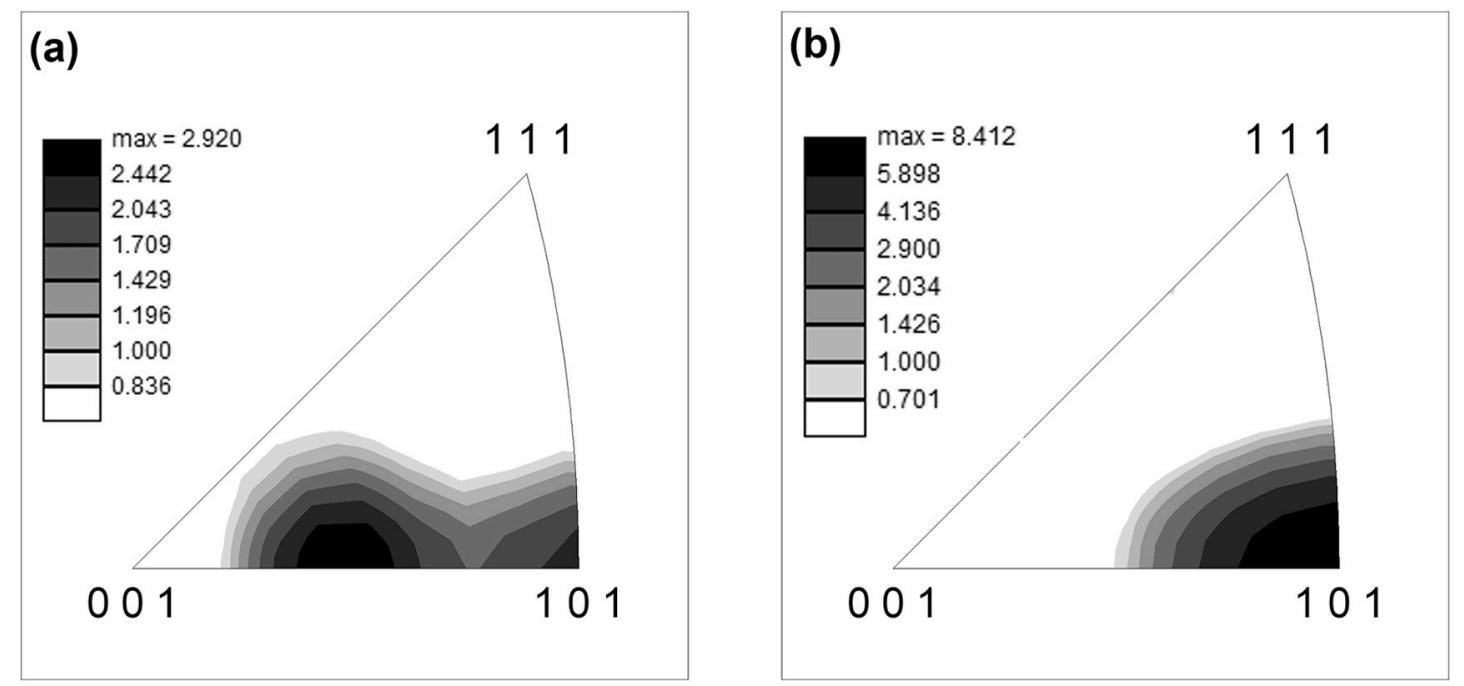

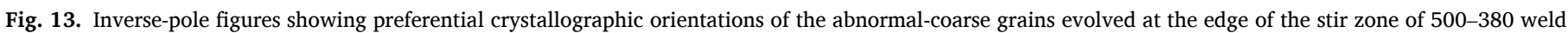
(a) and 1100-760 weld (b). In all cases, crystallographic orientations are shown relative to the extrusion/welding direction. See Section 4.1.3 for details.

Therefore, the mechanical behavior of the fully-annealed welds is virtually dictated by the microstructural processes occurring during FSW.

\subsubsection{Oxidation of butt surface}

It is important to point out that the tensile behavior of the highestheat-input welds (i.e., 1100-125 welds) was somewhat specific. These exhibited the lowest elongation-to-failure (Table 4) and were characterized by the failure in the stir zone (Figs. $4 \mathrm{~b}$ and 6 , Table 5). The nearly-brittle mechanism of the failure was of particular interest (Fig. 8).

A broadly similar behavior has been described in a number of previous works being ascribed to the crack propagation through the remnant butt line $[68,69]$. In scientific literature, this welding defect is sometimes referred to as "lazy S line" [68-70] or "zigzag line" [71]. It is observed preferentially in high-temperature welds [70] perhaps originating from oxidation of the prior butt surface during FSW. It is worth noting that its detrimental influence becomes particularly prominent after post-weld $\mathrm{T} 6$ tempering treatment [71]. It is likely that the thermal stresses induced during the water-quenching step of the solutionizing treatment exert a de-bonding effect, thus transforming the zigzag line into a crack.

From comparison with the literature data, it appears that the 1100-125 welds studied in the present work failed via de-bonding of the zigzag line. However, validation of this assumption requires further experimental work.

\section{Conclusions}

This work was undertaken to establish a relationship between welding conditions, annealing behavior, and mechanical performance of friction-stir welded 6061-T6 aluminum alloy. To this end, a series of welds was produced in a wide range of FSW conditions, underwent the standard T6 post-weld heat treatment, and then subjected to the transverse tensile tests. To provide a thorough insight into material response, the sample-scale EBSD mapping was used for microstructural analysis, and the digital image correlation technique was applied for interpretation of the tensile behavior. The main conclusions derived from this study were as follows.

(1) The sharp microstructural gradient inherent to the FSW process was found to result in a range of annealing phenomena during post-weld solutionizing treatment. Specifically, the abnormal grain growth was observed in the stir zone and the heat-affected zone, whereas the material in the thermo-mechanically affected zone experienced the static recrystallization. Hence, the microstructure distribution in the fully-annealed welds was concluded to be intrinsically inhomogeneous.

(2) In all cases, the abnormal grain growth resulted in $\sim 25$ $35^{\circ}<110>$ rotation of the original crystallographic texture. Accordingly, the microstructural coarsening process was suggested to be governed by the orientation-growth mechanism.

(3) In the entire studied range of FSW conditions, the welded material was found to be unstable against the abnormal grain growth during post-weld solutionizing treatment. However, a lowering of the FSW heat input promoted a formation of relatively finegrained microstructure in the fully-annealed welds, i.e., tended to suppress the catastrophic grain coarsening.

(4) Due to the relatively high strain-hardening ability inherent to the coarse-grained materials, the abnormal grains tended to suppress material flow in the stir zone during transverse tensile tests. This resulted in inhomogeneous strain distribution and degraded weld ductility. The tensile strain and subsequent failure were found to preferentially occur in the relatively fine-grained base material zone or the thermo-mechanically affected zone.

(5) The welds produced at the highest heat-input condition were found to fail in the stir zone via a nearly-brittle mechanism. This effect was attributed to a crack propagation through the remnant butt surface which has oxidized at high welding temperature and thus partially survived during FSW.

\section{CRediT authorship contribution statement}

Alexander Kalinenko: Investigation, Methodology, Formal analysis, Validation, Writing - review \& editing. Igor Vysotskii: Investigation, Methodology, Formal analysis, Validation, Writing - review \& editing. Sergey Malopheyev: Investigation, Methodology, Formal analysis, Validation, Writing - review \& editing. Sergey Mironov: Conceptualization, Data curation, Project administration, Writing original draft. Rustam Kaibyshev: Funding acquisition, Resources, Supervision, Writing - review \& editing.

\section{Declaration of competing interest}

The authors declare that they have no known competing financial interests or personal relationships that could have appeared to influence the work reported in this paper. 


\section{Acknowledgments}

This study was financially supported by the Russian Science Foundation, grant No. 19-49-02001. The authors are also grateful to the staff of the Joint Research Center "Technology and Materials" at Belgorod State National Research University for assistance in experimental work.

\section{Appendix A. Supplementary data}

Supplementary data to this article can be found online at https://doi. org/10.1016/j.msea.2021.141409.

\section{Data availability statement}

The raw/processed data required to reproduce these findings cannot be shared at this time as the data also forms part of an ongoing study.

\section{References}

[1] R.S. Mishra, Z.Y. Ma, Friction stir welding and processing, Mater. Sci. Eng. R 50 (2005) 1-78, https://doi.org/10.1016/j.mser.2005.07.001.

[2] P.L. Threadgill, A.J. Leonard, H.R. Shercliff, P.J. Withers, Friction stir welding of aluminum alloys, Int. Mater. Rev. 54 (2009) 49-93, https://doi.org/10.1179/ 174328009 X411136.

[3] Y.S. Sato, H. Watanabe, H. Kokawa, Grain growth phenomena in friction stir welded $1100 \mathrm{Al}$ during post-weld heat treatment, Sci. Technol. Weld. Join. 12 (2007) 318-323, https://doi.org/10.1179/174329307X197575.

[4] S. Mironov, K. Masaki, Y.S. Sato, H. Kokawa, Texture produced by abnormal grain growth in friction stir-welded aluminum alloy 1050, Metal. Mater. Trans. 44 (2013) 1153-1157, https://doi.org/10.1007/s11661-012-1596-4.

[5] D. Yadav, R. Bauri, A. Kauffmann, J. Freudenberger, Al-Ti particulate composite: processing and studies on particle twinning, microstructure and thermal stability, Metall. Mater. Trans. A 47 (2016) 4226-4238, https://doi.org/10.1007/s11661016-3597-1.

[6] S. Mironov, R. Kaibyshev, Abnormal grain growth in fine-grained aluminum produced by friction-stir welding, IOP Conf. Ser. Mater. Sci. Eng. 672 (2019), 012043.

[7] F.C. Liu, B.L. Xiao, K. Wang, Z.Y. Ma, Investigation of superplasticity in friction stir processed 2219Al alloy, Mater. Sci. Eng. 527 (2010) 4191-4196, https://doi.org/ 10.1016/j.msea.2010.03.065.

[8] M.M. Attallah, H.G. Salem, Friction stir welding parameters: a tool for controlling abnormal grain growth during subsequent heat treatment, Mater. Sci. Eng., A 391 (2005) 51-59, https://doi.org/10.1016/j.msea.2004.08.059.

[9] M.A. Safarkhanian, M. Goodarzi, S.M.A. Boutorabi, Effect of abnormal grain growth on tensile strength of Al-Cu-Mg alloy friction stir welded joints, J. Mater. Sci. 44 (2009) 5452-5458, https://doi.org/10.1007/s10853-009-3735-x.

[10] H.J. Liu, X.L. Feng, Effect of post-processing heat treatment on microstructure and microhardness of water-submerged friction stir processed 2219-T6 aluminum alloy, Mater. Des. 47 (2013) 101-105, https://doi.org/10.1016/j. matdes.2012.11.056.

[11] E. Cerri, P. Leo, Mechanical properties evolution during post-weld-heat treatments of double-lap friction stir welded joints, Mater. Des. 32 (2011) 3465-3475, https:/ doi.org/10.1016/j.matdes.2011.01.052.

[12] Z.L. Hu, X.S. Wang, Q. Pang, F. Huang, X.P. Qin, L. Hua, The effect of postprocessing on tensile property and microstructure evolution of friction stir welding aluminum alloy joint, Mater. Char. 99 (2015) 180-187, https://doi.org/ 10.1016/j.matchar.2014.11.015.

[13] Y.X. Huang, L. Wan, Z.L. Lv, S.X. Lv, L. Zhou, J.C. Feng, Microstructure and microhardness of aluminium alloy friction stir welds with heat treatment, Sci. Technol. Weld. Join. 21 (2016) 638-644, https://doi.org/10.1080/ 13621718.2016.1152748.

[14] S.J. Yuan, Z.L. Hu, X.S. Wang, Formability and microstructural stability of friction stir welded $\mathrm{Al}$ alloy tube during subsequent spinning and post weld heat treatment, Mater. Sci. Eng., A 558 (2012) 586-591, https://doi.org/10.1016/j. msea.2012.08.056.

[15] Q. Pang, J.H. Zhang, M.J. Huq, Z.L. Hu, Characterization of microstructure, mechanical properties and formability for thermomechanical treatment of friction stir welded 2024-O alloys, Mater. Sci. Eng., A 765 (2019) 138303.

[16] M.M.Z. Ahmed, B.P. Wynne, Post Weld Heat Treatment of Friction Stir Welded AA2017, TMS Light Metals, 2012, pp. 509-513.

[17] F.C. Liu, Z.Y. Ma, L.Q. Chen, Low-temperature superplasticity of Al-Mg-Sc alloy produced by friction stir processing, Scripta Mater. 60 (2009) 968-971, https:// doi.org/10.1016/j.scriptamat.2009.02.021.

[18] S. Malopheyev, S. Mironov, I. Vysotskiy, R. Kaibyshev, Superplasticity of frictionstir welded Al-Mg-Sc sheets with ultrafine-grained microstructure, Mater. Sci. Eng., A 649 (2016) 85-92, https://doi.org/10.1016/j.msea.2015.09.106.

[19] Y. Chen, H. Ding, J. Li, Z. Cai, J. Zhao, W. Yang, Influence of multi-pass friction stir processing on the microstructure and mechanical properties of Al-5083 alloy, Mater. Sci. Eng., A 650 (2016) 281-289, https://doi.org/10.1016/j. msea.2015.10.057.
[20] S. Mironov, K. Masaki, Y.S. Sato, H. Kokawa, Relationship between material flow and abnormal grain growth in friction-stir welds, Scripta Mater. 67 (2012) 983-986, https://doi.org/10.1016/j.scriptamat.2012.09.002.

[21] K. Chen, W. Gan, K. Okamoto, C. Kwansoo, R.H. Wagoner, The mechanism of grain coarsening in friction-stir-welded AA5083 after heat treatment, Metall. Mater. Trans. 42 (2011) 488-507, https://doi.org/10.1007/s11661-010-0426-9.

[22] M.A. Garcia-Bernal, R.S. Mishra, R. Verma, D. Hernandez-Silva, Influence of friction stir processing tool design on microstructure and superplastic behavior of Al-Mg alloys, Mater. Sci. Eng., A 670 (2016) 9-16, https://doi.org/10.1016/j. msea.2016.05.115.

[23] N. Kumar, R.S. Mishra, Thermal stability of friction stir processed ultrafine grained AlMgSc alloy, Mater. Char. 74 (2012) 1-10, https://doi.org/10.1016/j. matchar.2012.09.003.

[24] W. Gan, K. Okamoto, S. Hirano, K. Chung, C. Kim, R.H. Wagoner, Properties of friction-stir welded aluminum alloys 6111 and 5083, J. Eng. Mater. Technol. 130 (2008) 310071-3100715, https://doi.org/10.1115/1.2931143.

[25] M.A. Garcia-Bernal, R.S. Mishra, R. Verma, D. Hernandez-Silva, Inhibition of abnormal grain growth during hot deformation of friction stir processed $5083 \mathrm{Al}$ alloys, Mater. Sci. Eng., A 636 (2015) 326-330, https://doi.org/10.1016/j. msea.2015.03.094.

[26] Y. Birol, Evolution of grain structure across joints in friction stir welded EN AW 5083 H111 plates during thermal exposure, Mater. Sci. Technol. 29 (2013) 1283-1289, https://doi.org/10.1179/1743284713Y.0000000272.

[27] C.-Y. Lin, T.-S. Liu, L.-H. Chen, Microstructural variation and tensile properties of a cast 5083 aluminum plate via friction stir processing, Mater. Trans. 50 (2009) 2801-2807, https://doi.org/10.2320/matertrans.M2009049.

[28] A. Smolej, D. Klobcar, B. Skaza, A. Nagode, E. Slacek, V. Dragojevic, The superplasticity of friction stir processed Al5Mg alloy with additions of scandium and zirconium, Int. J. Mater. Res. 105 (2014) 1218-1226, https://doi.org/ 10.3139/146.111141.

[29] P. Nelaturu, S. Jana, R.S. Mishra, G. Grant, B.E. Carlson, Effect of temperature on the fatigue cracking mechanisms in A356 Al alloy, Mater. Sci. Eng., A 780 (2020) 139175, https://doi.org/10.1016/j.msea.2020.139175.

[30] G. Ipekoglu, S. Erim, G. Cam, Investigation into the influence of post-weld heat treatment on the friction stir welded AA6061Al-alloy plates with different temper conditions, Metal. Mater. Trans. 45 (2014) 864-877, https://doi.org/10.1007/ s11661-013-2026-y.

[31] E. Cerri, P. Leo, Influence of high temperature thermal treatment on grain stability and mechanical properties of medium strength aluminium alloy friction stir welds, J. Mater. Process. Technol. 213 (2013) 75-83, https://doi.org/10.1016/j. jmatprotec.2012.09.001.

[32] I. Vysotskiy, S. Malopheyev, S. Mironov, R. Kaibyshev, Pre-strain rolling as an effective tool for suppression of abnormal grain growth in friction-stir welded 6061 aluminum alloy, Mater. Sci. Eng., A 733 (2018) 39-42, https://doi.org/10.1016/j. msea.2018.07.026.

[33] I. Vysotskiy, S. Malopheyev, S. Mironov, R. Kaibyshev, Effect of pre-strain path on suppression of abnormal grain growth in friction-stir welded 6061 aluminum alloy, Mater. Sci. Eng., A 760 (2019) 206-213, https://doi.org/10.1016/j. msea.2019.05.118.

[34] KhA.A. Hassan, A.F. Norman, D.A. Price, P.B. Prangnell, Stability of nugget zone grain structure in high strength Al-alloy friction stir welds during solution treatment, Acta Mater. 57 (2003) 1923-1936, https://doi.org/10.1016/S1359. 6454(02)00598-0.

[35] I. Charit, R.S. Mishra, Abnormal grain growth in friction stir processed alloys, Scripta Mater. 58 (2008) 367-371, https://doi.org/10.1016/j. scriptamat.2007.09.052.

[36] G. Ipekoglu, S. Erim, G. Cam, Effects of temper condition and post weld treatment on the microstructure and mechanical properties of friction stir butt-welded AA7075 Al alloy, Int. Adv. Manuf. Technol. 70 (2014) 201-213, https://doi.org/ 10.1007/s00170-013-5255-8.

[37] C. Sharma, D.K. Dwivedi, P. Kumar, Effect of post weld heat treatments on microstructure and mechanical properties of friction stir welded joints of $\mathrm{Al}-\mathrm{Zn}-\mathrm{Mg}$ alloy AA7039, Mater. Des. 43 (2013) 134-143, https://doi.org/10.1016/j. matdes.2012.06.018.

[38] A. Goloborodko, T. Ito, X. Yun, Y. Motohashi, G. Itoh, Friction stir welding of a commercial 7075-T6 aluminum alloy: grain refinement, thermal stability and tensile properties, Mater. Trans. 45 (2004) 2503-2508, https://doi.org/10.2320/ matertrans. 45.2503.

[39] S. Ren, Z. Ma, L. Chen, Y. Zhang, Effects of post-weld heat-treatment and secondwelding on tensile properties of friction stir welded 7075-T651 aluminum alloy, Acta Metall. Sin. 43 (2007) 225-230.

[40] P. Han, C. Yang, J. Wang, B. Du, X. Liu, P. Xue, Z. Ma, D. Ni, Effects of solution heat treatment on friction stir welding joints of 7B04-O aluminum alloy, J. Mech. Eng. 51 (2015) 35-41.

[41] S.V. Sajadifar, G. Moeini, E. Scharifi, C. Lauhoff, S. Bohm, T. Niendorf, On the effect of quenching on postweld heat treatment of friction-stir-welded aluminum 7075 Alloy, J. Mater. Eng. Perform. 28 (2019) 5255-5265, https://doi.org/ 10.1007/s11665-019-04252-3.

[42] Y. Morisada, H. Fujii, T. Nagaoka, M. Fukusumi, Effect of friction stir processing with SiC particles on microstructure and hardness of AZ31, Mater. Sci. Eng., A 433 (2006) 50-54, https://doi.org/10.1016/j.msea.2006.06.089.

[43] S. Mironov, Y. Motohashi, R. Kaibyshev, Grain growth behavior in a friction-stir welded ZK60 magnesium alloy, Mater. Trans. 48 (2007) 1387-1395, https://doi. org/10.2320/matertrans.MRA2007040.

[44] M. Mosayebi, A. Zarei-Hanzaki, H.R. Abedi, A. Barabi, M.S. Jalali, A. Ghaderi, M. Barnett, The correlation between the recrystallization texture and subsequent 
isothermal grain growth in a friction stir processed rare earth containing magnesium alloy, Mater. Char. 163 (2020) 110236, https://doi.org/10.1016/j. matchar.2020.110236.

[45] H. Yoshioka, S. Fukumoto, A. Yamamoto, H. Tsubakino, K. Okita, T. Tomita, Effec of post weld heat treatment on mechanical properties and microstructures of friction stir welded AZ31B magnesium alloy, J. Jpn. Inst. Light Metals 58 (2008) 2-7.

[46] Y. Sun, H. Fujii, Effect of abnormal grain growth on microstructure and mechanical properties of friction stir welded SPCC steel plates, Mater. Sci. Eng., A 694 (2017) 81-92, https://doi.org/10.1016/j.msea.2017.04.008.

[47] Y.J. Li, R.D. Fu, D.X. Du, L.J. Jing, D.L. Sang, Y.P. Wang, Effect of post-weld heat treatment on microstructures and properties of friction stir welded joint of 32Mn-7Cr-1Mo-0.3N steel, Sci. Technol. Weld. Join. 20 (2015) 229-235, https:// doi.org/10.1179/1362171815Y.0000000001.

[48] H. Dawson, M. Serrano, S. Cater, E. Jimenez-Melero, Characterization of ODS steel friction stir welds and their abnormal grain growth behavior, Fusion Eng. Des. 135 (2018) 174-182, https://doi.org/10.1016/j.fusengdes.2018.07.021.

[49] Y. Li, R. Fu, Y. Li, Y. Peng, H. Liu, Abnormal grain growth in the heat affected zone of friction stir welded joint of $32 \mathrm{Mn}-7 \mathrm{Cr}-1 \mathrm{Mo}-0.3 \mathrm{~N}$ steel during post-weld heat treatment, Metal 8 (2018) 254, https://doi.org/10.3390/met8040254.

[50] F. Khodabakhshi, A. Simchi, A.H. Kokabi, A.P. Gerlich, M. Nosko, Effects of postannealing on the microstructure and mechanical properties of friction stir processed $\mathrm{Al}$ $\mathrm{Mg}-\mathrm{TiO}_{2}$ nanocomposites, Mater. Des. 63 (2014) 30-41, https://doi.org/10.1016/j matdes.2014.05.065.

[51] J. Guo, B.Y. Lee, Z. Du, B.G. Bi, M.J. Tan, J. Wei, Effect of nano-particle addition on grain structure evolution of friction stir-processed $\mathrm{Al} 6061$ during postweld annealing, J. Occup. Med. 68 (2016) 2268-2273, https://doi.org/10.1007/ s11837-016-1991-1.

[52] M.M. Moradi, H.J. Aval, R. Jamaati, Effect of pre and post welding heat treatment in SiC-fortified dissimilar AA6061-AA2024 FSW butt joint, J. Manuf. Process. 30 (2017) 97-105, https://doi.org/10.1016/j.jmapro.2017.08.014.

[53] T. Shibayanagi, M. Maeda, M. Naka, Microstructure and its high temperature stability in a friction stir processed 5083 aluminum alloy, J. Jpn. Inst. Light Metals 56 (2006) 347-353, https://doi.org/10.2464/jilm.56.347.

[54] S. Jana, R.S. Mishra, J.A. Baumann, G. Grant, Effect of process parameters on abnormal grain growth during friction stir processing of a cast $\mathrm{Al}$ alloy, Mater. Sci. Eng., A 528 (2010) 189-199, https://doi.org/10.1016/j.msea.2010.08.049.

[55] F. Humphreys, A unified theory of recovery, recrystallization and grain growth, based on the stability and growth of cellular microstructures-I. The basic model Acta Mater. 45 (1997) 4231-4240.

[56] F.J. Humphreys, A unified theory of recovery, recrystallization and grain growth, based on the stability and growth of cellular microstructures-II. The effect of second-phase particles, Acta Mater. 45 (1997) 5031-5039.

[57] I.V. Vysotskiy, S.S. Malopheyev, S.Y. Mironov, R.O. Kaibyshev, Optimization of friction-stir welding of 6061-T6 aluminum alloy, Phys. Mesomech. 23 (2020) 402-429, https://doi.org/10.1134/S1029959920050057.
[58] F.J. Humphreys, Quantitative metallography by electron backscattered diffraction, J. Micros. 195 (1999) 170-185, https://doi.org/10.1046/j.13652818.1999.00578.x.

[59] P.B. Prangnell, C.P. Heason, Grain structure formation during friction stir welding observed by the stop action technique, Acta Mater. 53 (2005) 3179-3192, https:// doi.org/10.1016/j.actamat.2005.03.044.

[60] R.W. Fonda, J.F. Bingert, K.J. Colligan, Development of grain structure during friction stir welding, Scripta Mater. 51 (2004) 243-248, https://doi.org/10.1016/j. scriptamat.2004.04.017.

[61] S. Mironov, K. Inagaki, Y.S. Sato, H. Kokawa, Effect of welding temperature on microstructure of friction-stir welded aluminum alloy 1050, Metal, Mater. Trans. A 46 (2015) 783-790, https://doi.org/10.1007/s11221-014-2651-0.

[62] A. Kalinenko, K. Kim, I. Vysotskiy, I. Zuiko, S. Malopheyev, S. Mironov, R. Kaibyshev, Microstructure-strength relationship in friction-stir welded 6061-T6 aluminum alloy, Mater. Sci. Eng., A 793 (2020) 139858, https://doi.org/10.1016/ j.msea.2020.139858.

[63] F.J. Humphreys, M. Hatherly, Recrystallization and Related Phenomena, second ed., Elsevier, Oxford, 2004.

[64] A. Heiderzadeh, S. Mironov, R. Kaibyshev, G. Cam, A. Simar, A. Gerlich, F. Khodabakhsh, A. Mostafaei, D.P. Field, J.D. Robson, A. Deschamps, P.J. Withers, Friction stir welding/processing of metals and alloys: a comprehensive review on microstructural evolution, Prog. Mater. Sci. (2020) 100752, https://doi.org/ 10.1016/j.pmatsci.2020.100752.

[65] I.S. Zuiko, S. Mironov, S. Betsofen, R. Kaibyshev, Suppression of abnormal grain growth in friction-stir welded $\mathrm{Al}-\mathrm{Cu}-\mathrm{Mg}$ alloy by lowering of welding temperature, Scripta Mater. 196 (2021) 113765, https://doi.org/10.1016/j. scriptamat.2021.113765.

[66] A.W. Thompson, M.I. Baskes, W.F. Flanagan, The dependence of polycrystal work hardening on grain size, Acta Metall. 21 (1973) 1017-1028, https://doi.org/ 10.1016/0001-6160(73)90158-2.

[67] M.F. Ashby, The deformation of plastically non-homogeneous materials, Phil. Mag. A 21 (1970) 399-424, https://doi.org/10.1080/14786437008238426.

[68] S. Ren, Z. Ma, L. Chen, Y. Zhang, Effects of post-weld heat-treatment and secondwelding on tensile properties of friction stir welded 7075-T651 aluminum alloy, Acta Metall. Sin. 43 (2007) 225-230.

[69] Z. Zhang, B.L. Xiao, Z.Y. Ma, Influence of post weld heat treatment on microstructure and mechanical properties of friction stir-welded 2014Al-T6 alloy, Adv. Mater. Res. 409 (2012) 299-304. https://doi.org/10.4028/www.scientific. net/AMR.409.299.

[70] Y. Besel, M. Besael, U.A. Mercado, Kakiuchi, Y. Uematsu, Influence of joint line remnant on crack path under static and fatigue loadings in friction stir welded $\mathrm{Al}$ Mg-Sc alloy, Fract, Struct. Integr. 10 (2016) 295-305, https://doi.org/10.3221/ IGF-ESIS.35.34.

[71] M. Dai, Z. Hu, X. Wan, Q. Pang, Effect of zigzag line on mechanical properties of joint after friction stir welding and heat treatment, Heat Treat. Met. 42 (2017) 46-50, https://doi.org/10.13251/j.issn.0254-6051.2017.07.012. 